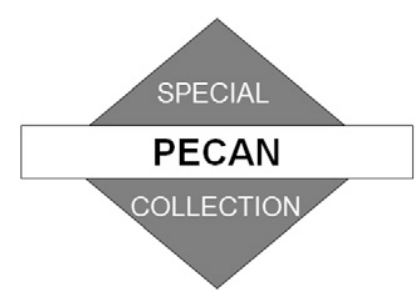

\title{
Wave Disturbances and Their Role in the Maintenance, Structure, and Evolution of a Mesoscale Convection System
}

\author{
SHUSHI ZHANG \\ Key Laboratory of Mesoscale Severe Weather, Ministry of Education, and School of Atmospheric Science, \\ Nanjing University, Nanjing, China \\ DAVID B. PARSONS \\ School of Meteorology, University of Oklahoma, Norman, Oklahoma \\ YUAN WANG \\ Key Laboratory of Mesoscale Severe Weather, Ministry of Education, and School of Atmospheric Science, \\ Nanjing University, Nanjing, China
}

(Manuscript received 30 November 2018, in final form 16 September 2019)

\begin{abstract}
This study investigates a nocturnal mesoscale convective system (MCS) observed during the Plains Elevated Convection At Night (PECAN) field campaign. A series of wavelike features were observed ahead of this MCS with extensive convective initiation (CI) taking place in the wake of one of these disturbances. Simulations with the WRF-ARW Model were utilized to understand the dynamics of these disturbances and their impact on the MCS. In these simulations, an "elevated bore" formed within an inversion layer aloft in response to the layer being lifted by air flowing up and over the cold pool. As the bore propagated ahead of the MCS, the lifting created an environment more conducive to deep convection allowing the MCS to discretely propagate due to CI in the bore's wake. The Scorer parameter was somewhat favorable for trapping of this wave energy, although aspects of the environment evolved to be consistent with the expectations for an $n=2$ mode deep tropospheric gravity wave. A bore within an inversion layer aloft is reminiscent of disturbances predicted by two-layer hydraulic theory, contrasting with recent studies that suggest bores are frequently initiated by the interaction between the flow within stable nocturnal boundary layer and convectively generated cold pools. Idealized simulations that expand upon this two-layer approach with orography and a wellmixed layer below the inversion suggest that elevated bores provide a possible mechanism for daytime squall lines to remove the capping inversion often found over the Great Plains, particularly in synoptically disturbed environments where vertical shear could create a favorable trapping of wave energy.
\end{abstract}

\section{Introduction}

Thunderstorms and mesoscale convection systems (MCSs) have long been recognized to have a nocturnal maximum over the central United States during the summer (e.g., Wallace 1975; Maddox 1980). These systems often originate when convection forms over the higher elevations to the west (Cotton et al. 1983), grows upscale, and becomes associated with an eastwardmoving envelope of deep convection (e.g., Parker and

Corresponding author: David B. Parsons, dparsons@ou.edu
Ahijevych 2007; Carbone and Tuttle 2008; Keenan and Carbone 2008). While the conventional view of MCSs typically includes a convectively generated cold pool that lifts potentially unstable air in a well-mixed boundary layer toward its level of free convection (i.e., Houze et al. 1989; Rotunno et al. 1988), Geerts et al. (2017) argues that the dynamics of nocturnal MCSs over this region are more complicated due to the presence of a stable nocturnal boundary layer (SBL) and a nocturnal low-level jet (NLLJ).

Previous investigations (e.g., Means 1952; Curtis and Panofsky 1958; Pitchford and London 1962; Maddox 
et al. 1979; Trier and Parsons 1993; Arritt et al. 1997; Tuttle and Davis 2006; Shapiro et al. 2016) have revealed that the NLLJ transports warm, moist air northward above the SBL resulting in an elevated maximum in convective available potential energy (CAPE). Recent work (e.g., Shapiro et al. 2018) has shown that the NLLJ is characterized not only by a peak in the southerly winds, but contains a westerly wind maximum that lies above the southerly peak. Parsons et al. (2019) found that on average this westerly layer was favorable for deep convection with significant CAPE and lower convective inhibition (CIN).

Nocturnal MCSs that are maintained by lifting of this potentially unstable air at and above the level of the NLLJ are typically considered to be "elevated." We do note, however, that different definitions have been used for the term "elevated" and Corfidi et al. (2008) showed that even surface-based systems can ingest air located above the boundary layer. In idealized simulations, Parker (2008) and French and Parker (2010) considered convection elevated when CAPE in the lowest $\sim 500 \mathrm{~m}$ vanished due to radiational cooling and convection transitioned to being maintained by bore lifting above the SBL. Bores playing a role in elevated convection is supported by numerous case studies over this region (Carbone et al. 1990; Wakimoto and Kingsmill 1995; Weckwerth et al. 2004; Knupp 2006; Wilson and Roberts 2006; Koch et al. 2008a,b; Tanamachi et al. 2008; Martin and Johnson 2008; Hartung et al. 2010; Marsham et al. 2011; Blake et al. 2017). These results are expected as Haghi et al. (2017) revealed that the interaction between the convectively generated cold pools and the SBL over this region typically resides in a partially blocked flow regime where bores will be generated (Rottman and Simpson 1989). These bores will be long lived as the wave energy is typically trapped by the "curvature" of vertical profile of the wind above the NLLJ (e.g., Crook 1988; Koch et al. 1991; Koch et al. 2008b; Haghi et al. 2017). Bores are associated with a net upward displacement of air and Parsons et al. (2019) and Loveless et al. (2019) recently found that the average net displacements associated with these bores ranged between 800 and $900 \mathrm{~m}$. Parsons et al. (2019) also showed that the significant lifting was not limited to the SBL, but occurred throughout the lower troposphere destabilizing the environment in the wake of a bore over areas of up to $10^{4} \mathrm{~km}^{2}$ initiating or aiding the maintenance of convection.

Parsons et al. (2019) also found that significant lifting by waves aloft often occurred ahead of convectively generated bores due either to separate wave responses generated by the bores or long-period gravity waves generated by deep convection. Such a long-period, deep tropospheric waves have also long been known to be associated with MCS. Studies (e.g., Bretherton and
Smolarkiewicz 1989; Nicholls et al. 1991; Pandya and Durran 1996; Mapes 1993) have generally focused on the $n=2$ mode gravity wave: a relatively slow-moving wave $\left(\sim 15 \mathrm{~m} \mathrm{~s}^{-1}\right)$ generated by heating (cooling) in the upper (lower) half of the troposphere. This $n=2$ mode with a vertical wavelength equal to the depth of the troposphere has lifting and cooling in the lower troposphere and is thus likely to play a role in initiating and maintaining convection (Schmidt and Cotton 1990; Lane and Reeder 2001; Fovell 2002; Lane and Zhang 2011; Birch et al. 2013). Fovell et al. (2006) also found that the interaction between a long-period gravity wave and shortperiod gravity waves could account for the discrete propagation of simulated midlatitude squall lines.

For tropical MCSs, Mapes (1993) proposed that the diabatic heat source creates a propagating gravity wave that causes updraft displacements at low levels in a mesoscale region surrounding the heating creating conditions more favorable for the development of new convection. Mapes (1993) referred to the wave as a buoyancy bore and proposed that tropical convection had a gregarious nature. Mapes (1993) proposal is similar to the destabilization of large areas by bores in this nocturnal environment as noted by Parsons et al. (2019).

Our study investigates the destabilization of the flow ahead of an MCS due to waves through studying an organized MCS that persisted into the night during the Plains Elevated Convection At Night (PECAN) field campaign (Geerts et al. 2017). The observed system was simulated utilizing the Weather Research and Forecasting (WRF) Model (Skamarock et al. 2008) and subsequently analyzed within the context of theories for bores and long-period gravity waves. Our findings suggest that bores can form aloft within capping inversions in the middle troposphere through the lifting of this stable layer by flow over the convectively generated cold pool (Fig. 1). This elevated bore removes the CIN allowing new convection to be generated ahead of the cold pool and the main body of the MCS. Fovell et al. (2006) called this process "forward convective initiation" leading to discrete propagation of the system and noted that its frequently occurrence in nocturnal squall lines.

\section{Observational analysis}

The MCS took place on 11-12 June 2015 during PECAN intensive observing period (IOP) 9. The surface observations at 2107 local standard time (LST) 11 June (Fig. 2) depict a quasi-stationary front near where convection first formed. The front separated warm, moist air with temperatures generally exceeding $\sim 28^{\circ} \mathrm{C}$ with dewpoints of $\sim 19^{\circ} \mathrm{C}$ from cooler, drier air to the north. The upper-air analysis at 850 and $500 \mathrm{hPa}$ 

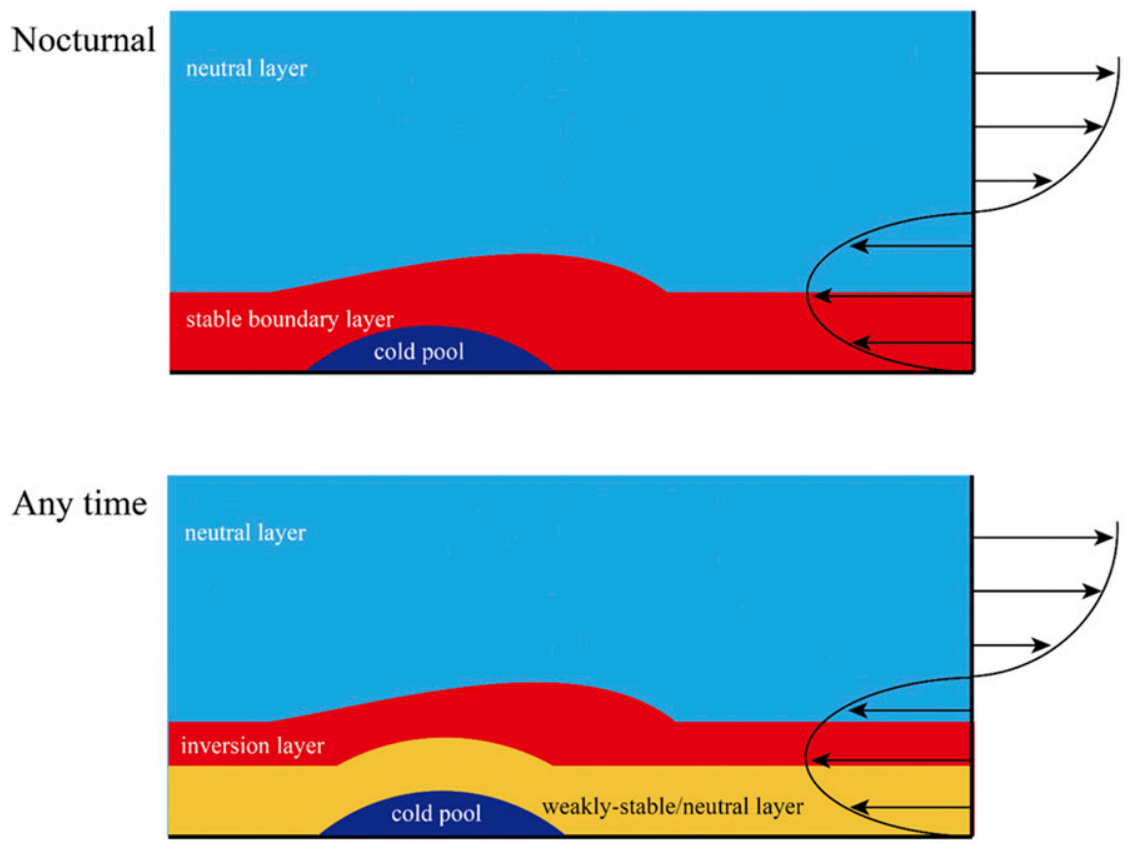

FIG. 1. Conceptual model of idealized bores for (top) the more commonly studied nocturnal case and (bottom) an elevated bore disturbance of the type investigated in this study. Note the elevated layer can be neutral, as in many idealized studies, or weakly stable as is sometimes observed.

(Fig. 3) indicates a synoptically disturbed situation with a low pressure center at $850 \mathrm{hPa}$ evident with a trough extending to the southwest. The strong flow at $850 \mathrm{hPa}$ ahead and parallel to the trough indicates the NLLJ was likely impacted by these synoptic disturbances (e.g., Uccelini and Johnson 1979). At $500 \mathrm{hPa}$, a short-wave trough was evident behind the surface stationary front (Fig. 3b). A quasi-stationary front and an upper-level trough are commonly found in the genesis region of nocturnal MCSs (e.g., Maddox 1983).

Without this synoptic forcing, conditions were not conducive for deep convection as the sounding taken from Lamont, Oklahoma, at 1900 LST 11 June ahead the surface front (Fig. 4a) reveals modest surfacebased CAPE $\left(\sim 830 \mathrm{~J} \mathrm{~kg}^{-1}\right)$, relatively large surfacebased CIN $\left(-150 \mathrm{~J} \mathrm{~kg}^{-1}\right)$ and a strong inversion based at $\sim 800 \mathrm{hPa}$. While the sounding at PECAN fixed profiling site FP2 at Greensburg, Kansas (Fig. 4b), closer to the quasi-stationary front provides evidence for spatial variations in this synoptically disturbed environment. For example, the Greensburg sounding has low-level northerlies (unfortunately a portion of the boundary layer winds are missing). Both Lamont and Greensburg soundings contain a capping inversion, which is significantly higher in the Greensburg sounding (at $\sim 700 \mathrm{hPa}$ ). The thermodynamics at Greensburg are more favorable for deep convection with CAPE of
$1423 \mathrm{~J} \mathrm{~kg}^{-1}$ and negligible CIN for surface-based parcels (Fig. 4b).

In this environment, a line of convection initially formed near the surface front at $\sim 1700$ LST. The structure and evolution of the MCS is shown in the radar reflectivity from VNX (Fig. 5), the nearest operational radar to the system. Considerable along-line variations in the reflectivity pattern were evident early in the MCS lifetime, at 2130 and 2200 LST (Figs. 5a,b). A series of arching radar fine lines were generated by these line segments that subsequently moved out ahead of the MCS (Fig. 5). Convection developed in the wake of these fine lines. For example, the first fine line at 2230 LST (Fig. 5c), formed at the northeast end of the convective line around 2130 LST and moved away from the convection. Scattered CI took place behind this fine line as it moved ahead of the system (Fig. 5d). The CI continued as the system grew upscale and the fine line dissipated (Fig. 5e). During the next several hours, a second well-defined fine line formed (Fig. 5f) and propagated ahead of the MCS with widespread CI again taking place behind its leading edge (not shown). The tendency for fine lines to form and propagate ahead of the precipitation with CI taking place in their wake meant that the MCS was discretely propagating rather than moving as a leading line-trailing stratiform MCS. Such radar fine lines in the nocturnal environment are often associated 


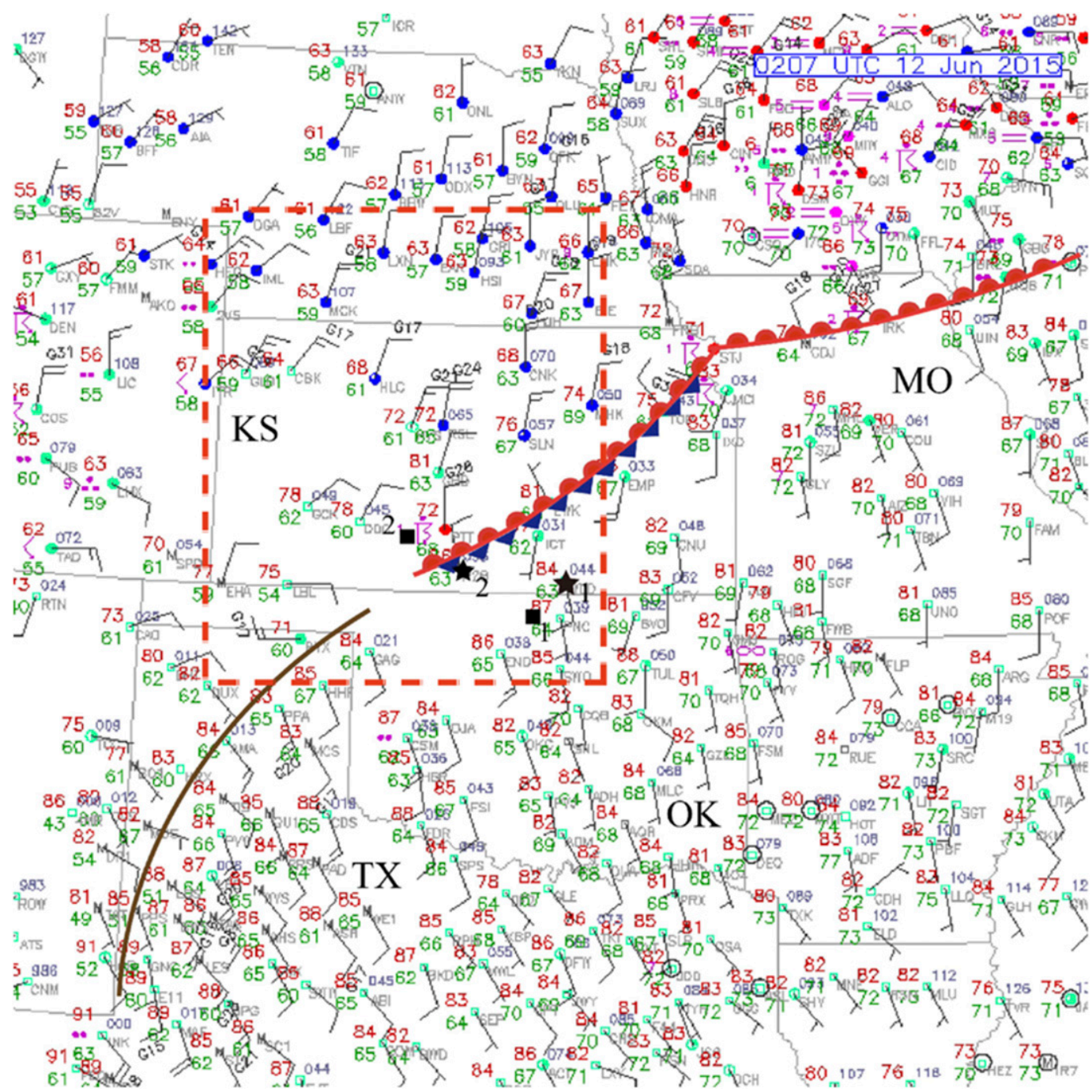

FIG. 2. Meteorological surface station data at 2107 LST 11 Jun 2015 (note the MCS occurs generally within the central time zone so that LST $=\mathrm{UTC}-5 \mathrm{~h}$ ) with the locations of the stationary front and warm front (defined from the operational analysis) indicated using conventional synoptic symbols. The brown solid line indicates the location of the dryline. The black stars, labeled 1 and 2, indicate the surface sites WLD and P28, respectively. The black rectangles labeled 1 and 2 indicate the sounding location of ARM (Lamont) and FP2 (Greensburg). The dashed red rectangle indicates the PECAN domain.

with cold pools, bores, gravity waves and solitons in the nocturnal environment (e.g., Wilson and Roberts 2006; Koch et al. 2008a,b; Haghi et al. 2017, 2019; Parsons et al. 2019).

The radial velocity data at VNX (Fig. 6) provides insight into the nature of the radar fine lines observed with this MCS. At 2130 LST, the fine line marked the leading edge of strong flow emanating from the system suggestive of the outflow associated with a convectively generated cold pool (Fig. 6a). At 2200 LST (Fig. 6b), as the boundary moved away from the MCS, the strong outflow from the system was restricted to the leading edge of the fine line. Roughly $30 \mathrm{~min}$ later (Fig. 6c), the disturbance was still evident, but the strong flow away from the system was no longer present. At 2300 LST (Fig. 6d), the radial velocity profile took on an appearance of an undular bore with a series of disturbances in the wind field. The evolution of the flow is similar to what is expected to occur with a convectively generated cold pool transitioning into a bore (i.e., Haghi et al. 2017; Chipilski et al. 2018). This fine line could be subsequently tracked in the radial velocity data until 2330 LST (Fig. 6e), somewhat longer than in the reflectivity data (Fig. 5). Within the MCS, a series of fine lines that formed behind the first fine line are also evident in the radial velocity data (Fig. 6). These features again 

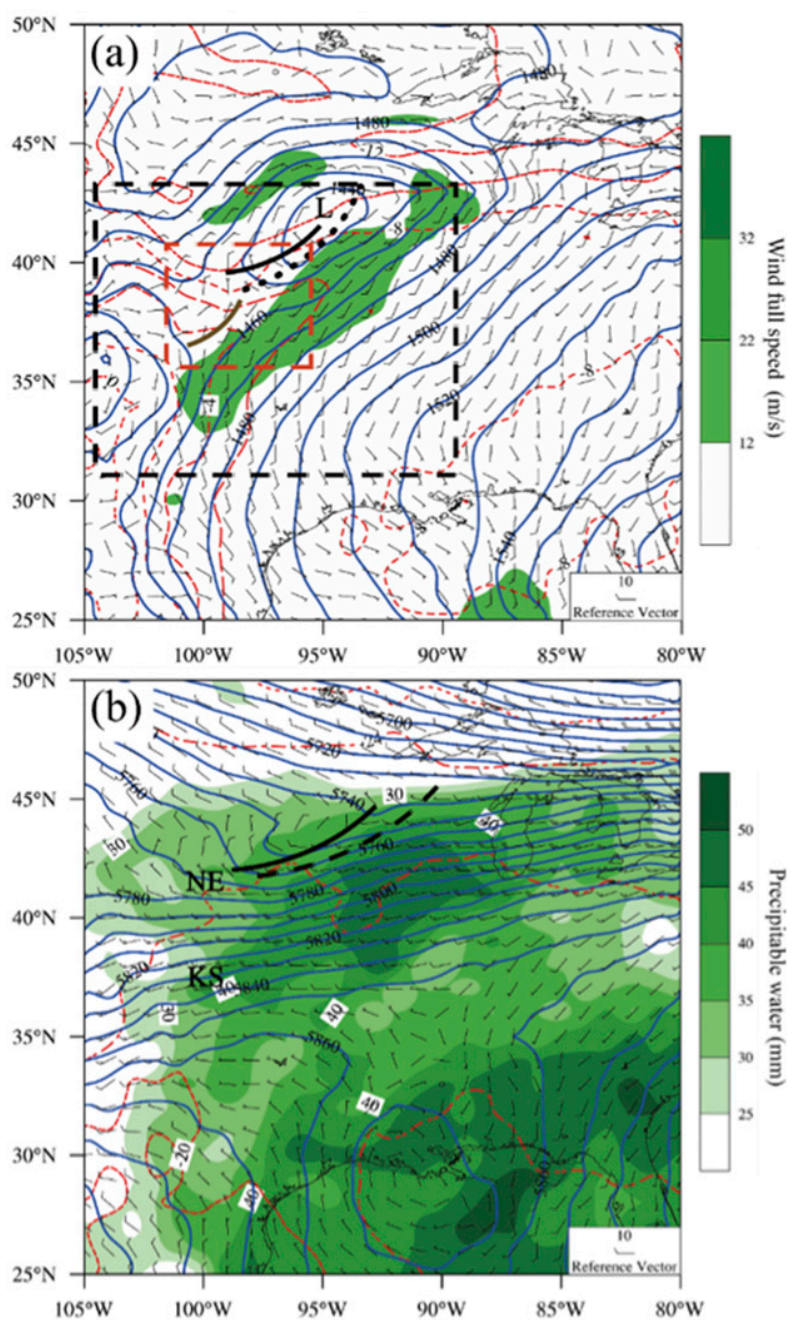

FIG. 3. Geopotential height (solid blue contour; m), temperature (dashed red contour; ${ }^{\circ} \mathrm{C}$ ), and wind barbs (one full barb $=10 \mathrm{~m} \mathrm{~s}^{-1}$ ) at 1900 LST 11 Jun 2015 at (a) 850 and (b) $500 \mathrm{hPa}$. Also in (a) wind speeds $>12 \mathrm{~m} \mathrm{~s}^{-1}$ are green shaded $\left(\mathrm{m} \mathrm{s}^{-1}\right)$, black bold lines indicate the location of a trough at 1900 LST 11 Jun, black dotted lines indicate the location of a trough at 0100 LST 12 Jun. The dashed black and dashed red rectangles indicate the area shown in Fig. 2 and PECAN domain, respectively. In (b) precipitable water is green shaded $(\mathrm{mm})$, black bold lines indicate the location of a trough at 1900 LST 11 Jun, and the black dashed line indicates the location of the convection initiation at 1700 LST 11 Jun.

initially corresponded to flow away from the MCS (Fig. 6) consistent with their origin as a convectively generated cold pool transitioning to a bore. The generation of a series of outflows by the various line segments and their subsequent evolution (Figs. 5 and 6) resulted in a complex flow behind the leading edge of the fine lines with alternating flow toward and away from the system (Fig. 6b). The outflows became associated with along-line variations in the general reflectivity pattern (i.e., Figs. 5e,f). This structure was observed in other nocturnal MCSs observed during PECAN and was referred to in Geerts et al. (2017) as convective fingers.

These fine lines were also associated with disturbances in the surface meteorological fields (Fig. 7). The fine line first reached the surface site P28 prior to 2130 LST (Fig. 5a). At this site, a steeping in the rate of the decrease in the surface temperature occurred at $\sim 2050$ LST followed by a wind shift to northerly flow. This evolution suggests the arrival of a convectively generated cold pool, consistent with outflow previously shown in the Doppler radar images (Fig. 6). A small pressure rise and some warming also occurred near or just prior to the passage of the fine line at P28 (Fig. 7a) at $\sim 2110$ LST. The most pronounced feature observed in the surface data at P28, however, is the variations in the surface fields following the passage of the fine line. These variations include an oscillation in the pressure field of several hectopascals, slight warming followed by sharp temperature decreases, and a shift in wind direction between southerly and northerly flow. This behavior is also consistent with the complexity of the radial velocity pattern (Fig. 6) and the reflectivity (Fig. 5). Overall, it is clear that the nocturnal system was more complicated than a "conventional" leading convective line, trailing stratiform system driven by a convective outflow. The CI taking place behind the fine lines is consistent with a discretely propagating system, which seems to be a common occurrence for bore-maintained convection.

A subsequent evolution of the MCS with time is evident from the surface data at WLD (Fig. 7b). This evolution included a tendency for the multiple temperature drops to coalesce toward a single strong decrease in temperature $\left(\sim 7.5^{\circ} \mathrm{C}\right)$ and a general increase in the magnitude of the pressure and wind shift. In addition to the cold pool, the surface data also contained a steep pressure rise $(\sim 2 \mathrm{hPa}$ took place in $\sim 10 \mathrm{~min})$ with little change in the winds or temperature (see red arrow labeled 1 in Fig. 7b) that was clearly evident ahead of the cold pool at the time the first dissipating fine line reached WLD (Fig. 6e). Given the steep pressure rise, a lack of a temperature drop, and the evolution of the radial velocity field away from a strong outflow shown in Fig. 6, this feature is likely an atmospheric bore. Evidence for this statement can be found in the Haghi et al. (2017) study that utilized past analyses in the literature to classify fine lines in the nocturnal environment. In that study, fine lines were classified as bores if they had a pronounced semipermanent pressure rise in excess of $0.5 \mathrm{hPa}$ and had either no change in surface temperature or a temperature rise as potentially warm air was mixed down from aloft within the stable nocturnal boundary layer. 

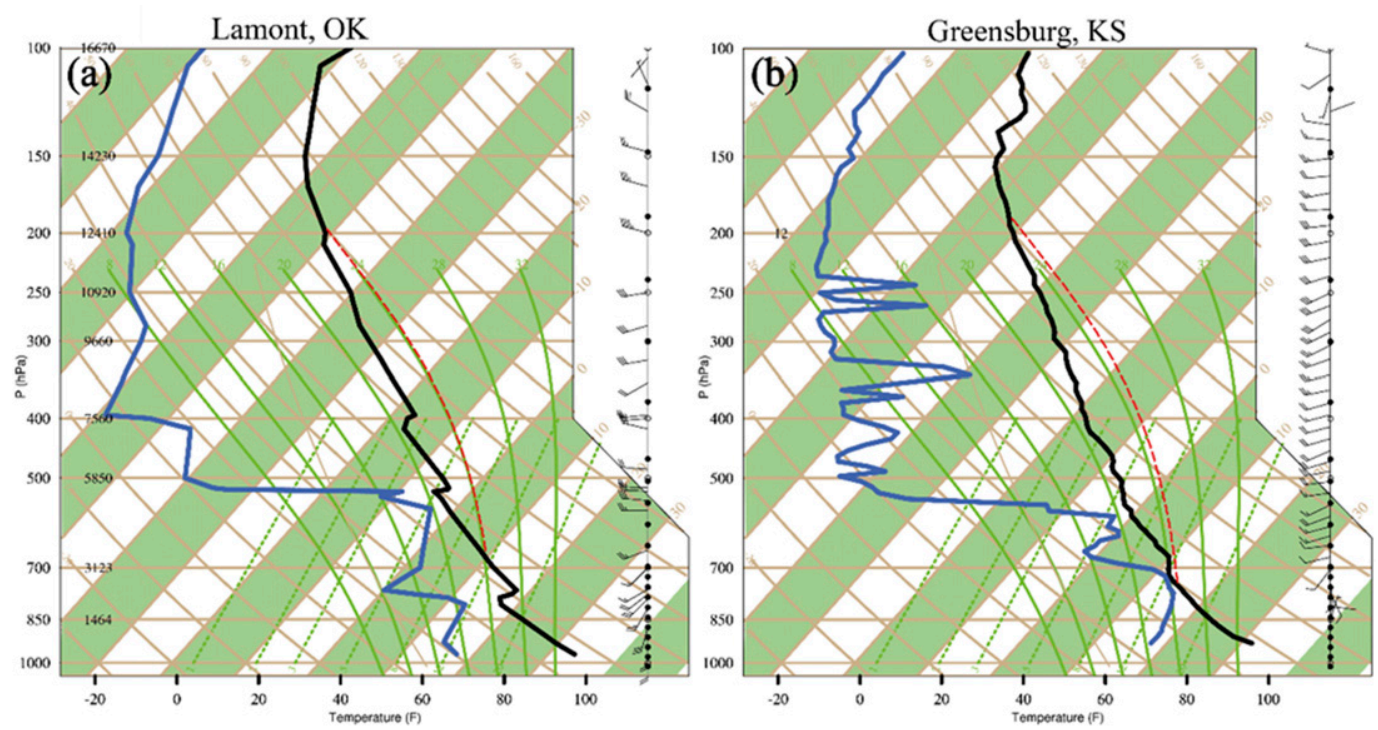

FIG. 4. Skew $T$ plots in standard meteorological format for radiosondes launched at 1900 LST 11 Jun 2018 from (a) the ARM site at Lamont and (b) the FP2 site at Greensburg. Courtesy of the University of Wyoming sounding archival and access system and the PECAN field archive.

In summary, the observations suggest that the MCS had a relatively complex structure and evolution compared to the conceptual model of a propagating squall line. From the radar data and the limited surface observations, we propose that the MCS generated multiple cold outflows that impacted the structure of and evolution of the system. These outflows interacted with the quasi-stationary front to transition the flow into an advancing cold front as described in the operational analyses. These outflows appeared to transition into bores with a pressure jump that persisted after the fine line was difficult to detect or was no longer evident. CI took place in the wake of this disturbance and thus played a role in the organization and maintenance of the MCS through discrete propagation as the CI took place in their wake. The role of the bore in maintaining the system was likely significant given that the prefrontal environment had modest CAPE and significant CIN (Fig. 4a).

\section{Model configuration}

Insight into the dynamics of the wave disturbances and their role in the MCS was obtained through simulations with version 3.7.1 of the WRF Model that utilized the Advanced Research core (Skamarock et al. 2008). The simulation was conducted for $36 \mathrm{~h}$ and was initialized at 1200 LST 10 June. This initial time was chosen to allow enough "spinup" in the simulation to more accurately represent the structure of the MCS and the wave disturbances. Our simulation employed three nested domains (Fig. 8). The inner domain had a convection-permitting 1-km horizontal resolution located to capture the evolution of the MCS and the waves disturbances. The larger-scale synoptic circulations were captured on the outer domain with two-way nesting utilized in which the outer domain provided boundary values for the inner grid, while allowing the inner grid to influence the outer domain.

The simulation utilized 49 vertical levels for all three domains with a staggered gird in the vertical. The first model level was at $\sim 25 \mathrm{~m}$ AGL with a vertical spacing of $\sim 70 \mathrm{~m}$ in the lowest portions of the domain that gradually increased with height to a spacing of $\sim 300 \mathrm{~m}$ near the top of the domain $\sim 50 \mathrm{hPa}$. The physical parameterizations (Table 1) followed Blake et al. (2017), since that study was able to accurately represent nocturnal MCS and bores in this region. The simulation was driven by the NCEP North American Regional Reanalysis (NARR) (Mesinger et al. 2006). The special observations taken during PECAN were not assimilated into the initial conditions largely since the PECAN mobile facilities were deployed too far to the west and the fixed sites were reserved for evaluation of the model predictions.

\section{Overview of the simulation}

The WRF simulation performed relatively well in representing the observed system as evident from comparisons between the evolution of the MCS in the observations (Fig. 5) and the simulation (Fig. 9). The model simulated the transition from a narrow convective 


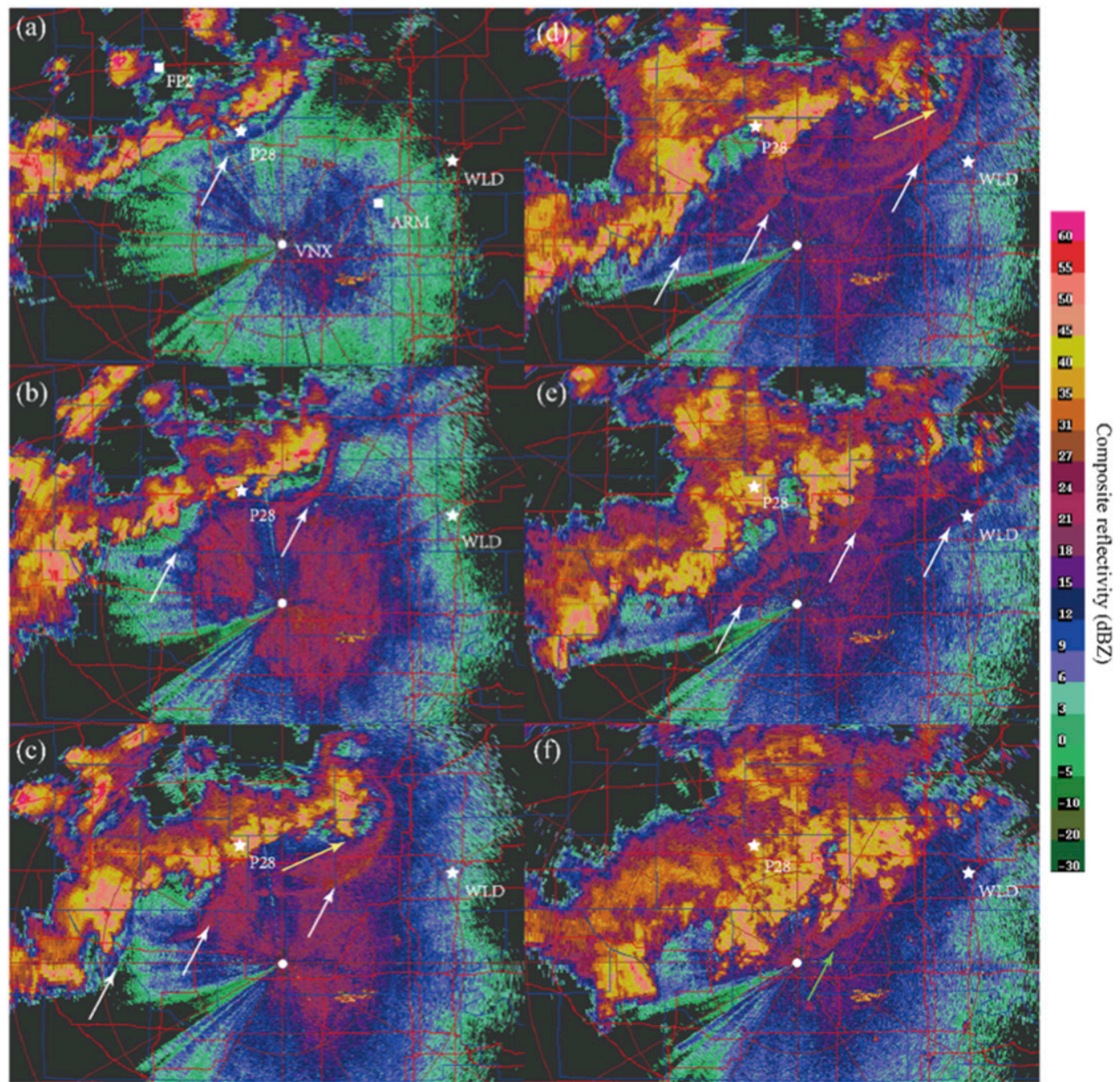

FIG. 5. VNX radar reflectivity (dBZ) from low-level surveillance scans when the (a)-(e) first and (f) second sets of radar fine lines was generated. The color scale for the radar reflectivity is shown on the right. Times are (a) 2130, (b) 2200, (c) 2230, (d) 2300, (e) 2330, and (f) 0000 LST. White (green) arrows indicate the first (second) fine lines and yellow arrows indicate $\mathrm{CI}$ behind fine lines. The white stars indicate the approximate locations of the surface sites Winfield, Kansas (WLD) and Pratt, Kansas (P28). The white rectangles indicate the sounding locations of ARM (Lamont) and FP2 (Greensburg). The white circle indicates the location of VNX radar.

line to the MCS, although the simulated system was located to the north of the observed storm. The simulated system had a relatively broad area of convection with composite reflectivity greater than $50 \mathrm{dBZ}$ compared to a narrower band in the observations. Such differences are known to occur due to shortcomings in microphysical parameterizations (Morrison and Milbrandt 2015). The simulation also transitioned from a continuous leading line of convection to more scattered convective cells initiated ahead of the main body of the storm and included some banded structures reminiscent of the observed fingers and CI in the wake of the second fine line (Fig. 9).

The time evolution of the surface meteorological fields from the simulation (Fig. 10) is shown for comparison with the observations (Fig. 7) noting the position of the simulated convection meant that the model fields were located to the north of the surface stations shown in the observations to better capture the evolution of the system. While the MCS was relatively well represented, the surface variables reveal differences between the observed and simulated environment. For example, while the temperature in the environment ahead of the cold air in the observations remained relatively steady with time (Fig. $7 b$ ), a more pronounced cooling trend was noted in the simulation during the late evening hours (Fig. 10b). An accurate representation of the surface temperature and winds and the nature of the SBL in the NLLJ environment is a 


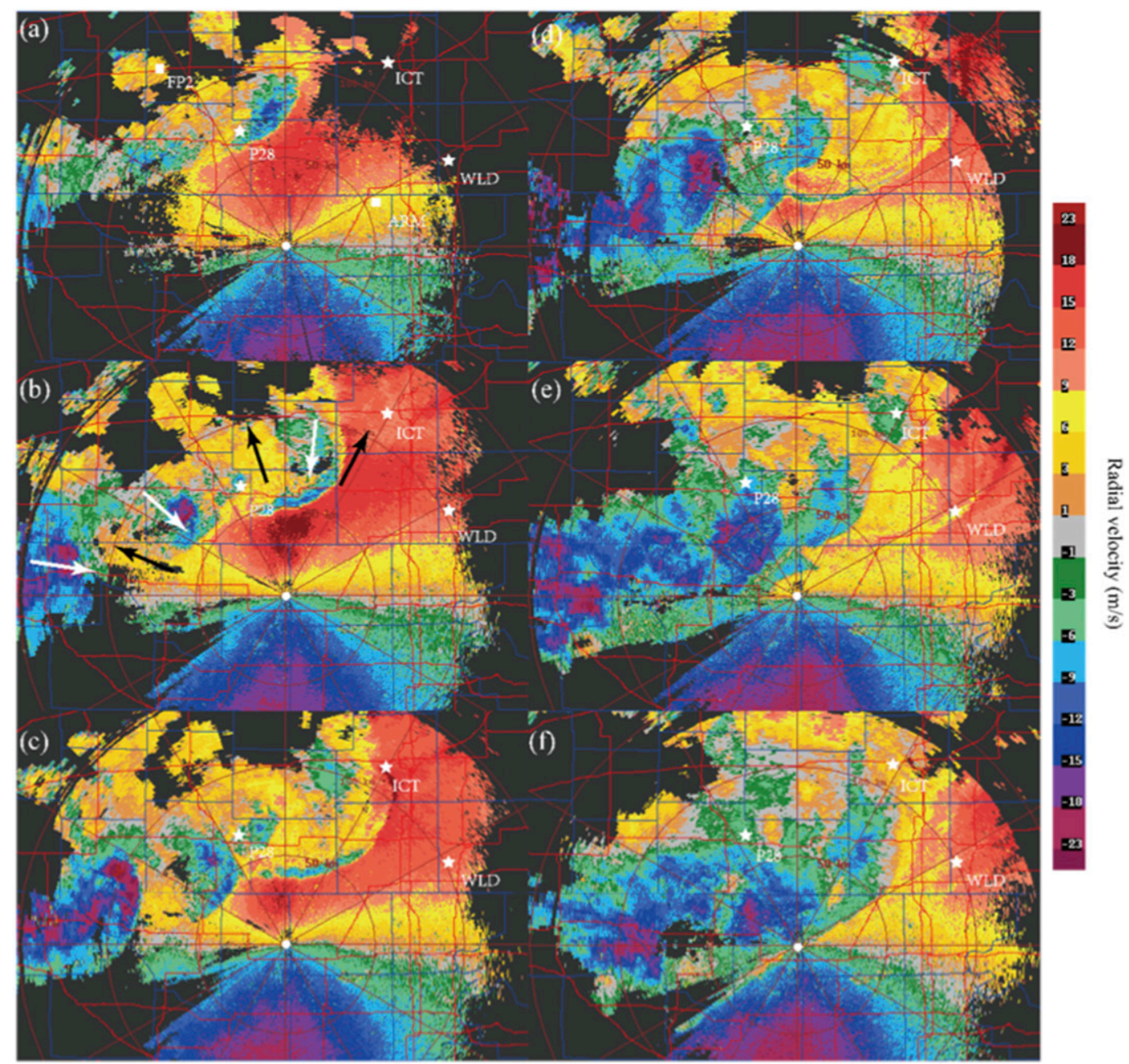

FIG. 6. As in Fig. 5, but for radial velocities $\left(\mathrm{m} \mathrm{s}^{-1}\right)$. Oscillations in the radial velocity toward and away from the radar indicated with white and black arrows, respectively.

challenge for numerical models with the results dependent on the type of boundary layer scheme (e.g., Zhang and Zheng 2004; Zhang et al. 2013; Jahn and Gallus 2018). For example, Jahn and Gallus (2018) noted that the MYNN boundary layer scheme used herein can result in a cool bias in WRF simulations of this environment, although Blake et al. (2017) and Johnson and Wang (2017) argue that the scheme better represents aspects of the nocturnal convection.

The time evolution of the meteorological fields in the observations (Fig. 7a) and the simulation (Fig. 10a) show a similar overall impact of the cooling generated by the frontal advection and the convectively generated cold pools with temperatures eventually lowering to $\sim 20^{\circ} \mathrm{C}$. However, while the simulation shows that the cooling occurs in two steps (Fig. 10a), the observations had a more complex structure (Fig. 7a). This finding is consistent with the differences in the precipitation field
(Figs. 5 and 9) suggesting that the observed system simply had more along-line variation than the simulation. The surface variables from the model (Fig. 10b) do, however, reveal a sharp pressure rise ahead of the system consistent with the bore disturbance emanating from the MCS (at $\sim 2150$ LST) and a later second pressure rise and a relative warming (slowing of the temperature decrease) ahead of the arrival of the cold pool (at $\sim 2350$ LST). This tendency raises the possibility of a second bore-like disturbance associated with the MCS as found earlier in the observed time series.

An advantage of the simulation is that the spatial variations in the thermodynamic quantities are more readily evident and can be related to the behavior of the MCS in contrast to the relatively sparse surface observational network. In the simulation, the preconvective environment located at the SW end of the stationary front was associated with low-level convergence and a 
(a)

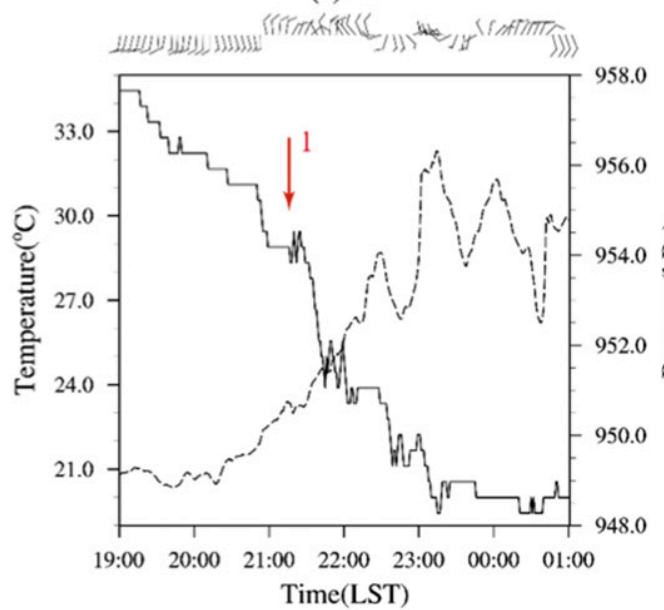

(b)

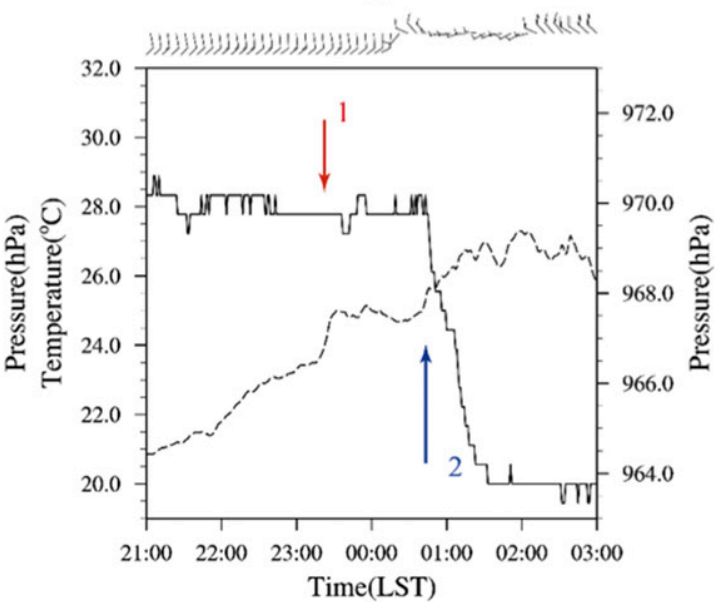

FIG. 7. Time series of temperature (solid line; ${ }^{\circ} \mathrm{C}$ ), wind barbs, and pressure (dashed line; hPa) at stations (a) P28 and (b) WLD. The red arrows labeled " 1 " in (a) is the possible origin of the bore through tracking of the radar fine lines. The blue arrow blue arrow labeled " 2 " indicates a cold pool consistent with the interpretation of the radar data in Figs. 5 and 6.

corridor of high CAPE at $1 \mathrm{~km}$ AGL along the front and dryline (Fig. 11a). The convection subsequently developed along the leading edge of the front (Fig. 11b). The trajectories (not shown) indicated that these air parcels in the inflow area were lifted and traveled toward the northeast along the front and were subsequently ingested into the convective line. The narrow corridor of high CAPE and the development of convection along the front is evidence of the role of mesoscale boundaries and synoptic forcing in initiating the convection. At $1 \mathrm{~km}$ AGL, the magnitude of CAPE within this corridor decreased as the night progressed and the CIN locally increased (Figs. 11b,c). Surfaces fields (not shown) reveal a similar spatial distribution, but higher CAPE than at $1 \mathrm{~km}$.

Using model output from the 1-km domain, a series of vertical cross sections of winds and CAPE, calculated using the parcel characteristics at each level in the model (Fig. 12) are displayed along a NW-SE orientation to illustrate the evolution and structure of the ambient environment and the convection. Significant CAPE was found in the lower levels ahead of the system throughout

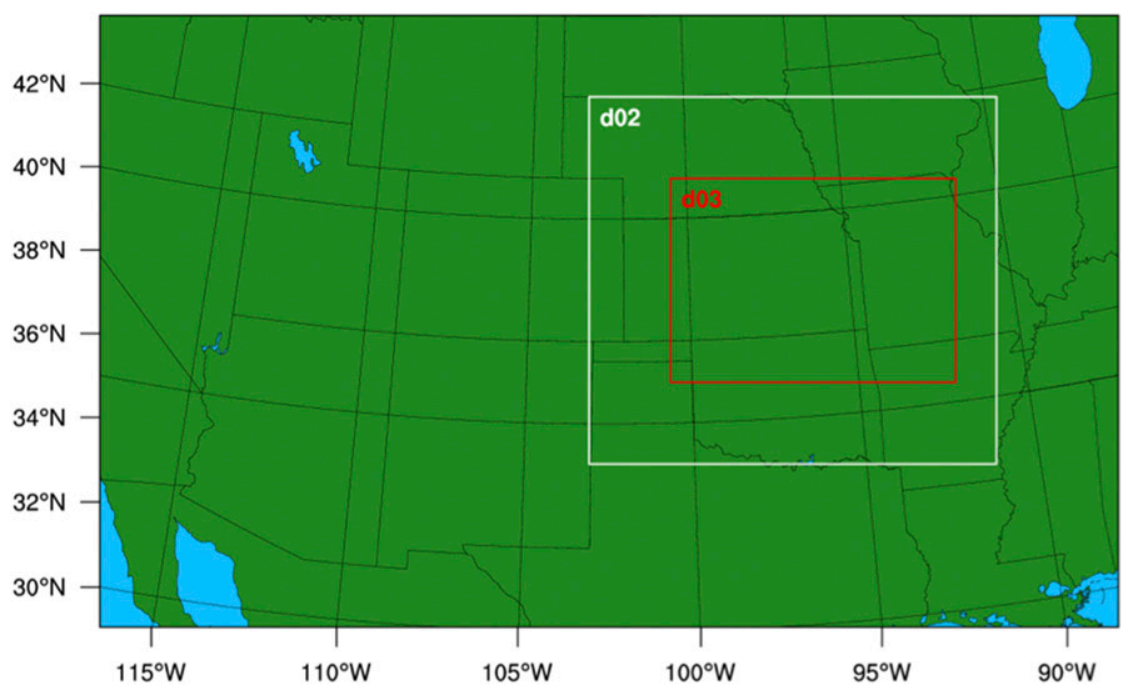

FIG. 8. Domain configurations used in the WRF Preprocessing System and in the simulations. The figure encompasses the outer domain with a horizontal grid spacing of $9 \mathrm{~km}$. The two inner domains at 3- and 1-km resolution are indicated by the boxes labeled d02 and d03, respectively. 
TABLE 1. Parameterization schemes utilized by the WRF-ARW Model.

\begin{tabular}{lll}
\hline \hline Atmospheric process & Parameterization scheme & \multicolumn{1}{c}{ Reference and notes } \\
\hline Longwave radiation & RRTM & Mlawer et al. (1997) \\
Shortwave radiation & New Goddard & Chou and Suarez (1999) \\
Cloud microphysics & Morrison & Morrison et al. (2009) double-moment scheme \\
Land surface & Noah BMJ & Ek et al. (2003) \\
Convection & BMJ & Janjić (1994), 9- and 3-km domains only \\
PBL & MYNN, level 2.5 & Nakanishi and Niino (2004) \\
Surface layer & MYNN & Nakanishi and Niino (2004) \\
\hline
\end{tabular}

the night with magnitudes increasing beginning at $\sim 2000$ LST (Fig. 12a). While the maximum in the CAPE is located above the surface at later times, after 2130 LST (Fig. 12d), the flow in the lowest $\sim 1 \mathrm{~km}$ maintains relatively high CAPE with the absence of a strong nocturnal stable boundary layer (see the potential temperature contour in Fig. 14). The vertical distribution of CAPE is, therefore, quite different than the expected nocturnal environment in this region with a stable boundary layer with high values of CAPE limited to heights near and above the NLLJ (Geerts et al. 2017; Blake et al. 2017; Parsons et al. 2019). The difference is perhaps due to the presence of secondary circulations associated with the front (e.g., Trier et al. 1991).

The airflow and the CAPE fields in the vertical cross section (Fig. 12) shows evidence of low-level outflow moving ahead of the MCS with the first shallow pulse evident at 2100 LST (Fig. 12c), and then dissipating significantly by 2300 LST (Fig. 12g). The lifting from this disturbance was associated with lifting of the area of higher CAPE. A second stronger outflow is evident at 2300 LST (Fig. 12g) and subsequently moves out ahead of the system as the first one dissipates. A subtler feature (labeled with the red arrow 1) is a maximum in low-level CAPE and lifting that propagates ahead of the outflow and is also associated with a significant decrease in the level of free convection (LFC). This decrease in the height of the LFC, first evident at 2030 LST in Fig. 12b, moves ahead of both the MCS and the cold pool with time. This feature appears associated with lifting of the CAPE and a mesoscale maximum in CAPE on the order of $\sim 50 \mathrm{~km}$ at $2300 \mathrm{LST}$ (Fig. $12 \mathrm{~g}$ ).

The corresponding vertical cross section of CIN (Fig. 13) reveals a dramatic reduction in CIN take place at increasing distances ahead of the system at nearly the same location as the decrease in the LFC associated with the disturbance in the model surface field (recall that a similar surface disturbance was evident in the observations). The removal of CIN covers a large area in the wake of this disturbance. Thus, the impact of this disturbance is to make the inflow more susceptible to the initiation of deep convection through eliminating CIN and lowering the LFC, while also increasing the intensity of deep convection through modestly increasing the CAPE.

The corresponding cross section of vertical velocity and potential temperature (Fig. 14) illustrates the physical explanation for this evolution in the thermodynamics. Weak up- and downdrafts are evident ahead of the system generally in the upper half of the troposphere ahead of the MCS early in its life cycle (Figs. 14a,b) with transient areas of ascent (Figs. 14c,e). The predominant features, however, are two pulses of cold air in the potential temperature field that are associated with strong ascent. The first pulse of lifting was clearly evident near the leading edge of the system at 2000 LST (see red arrow labeled "1" in Fig. 14b), while the second strong area of lifting in the lower levels was associated with a second pulse of cold air first evident at 2300 LST (blue arrow labeled " 2 " in Fig. 14g). The two sustained pulses of upward vertical motion (the red arrow labeled " 1 " and blue arrow labeled "2" in Fig. 14) explain the evolution in the CAPE, CIN, and LFC with sustained lifting (indicated with the red arrow labeled " 1 ") resulting in the reduction in CIN, modest increase in CAPE, and lowering of the LFC. Hence, the environment is more conducive to deep convection consistent with the observed and simulated CI in the wake of the first disturbance.

A closer examination of the potential temperature and vertical motion reveals that this pulse of lifting was initially quite close to the cold pool and then moved ahead with time (Fig. 14). The result was that the ascent separated into two branches, one associated with the leading edge of the shallow cold pool and the other aloft at heights of $\sim 2000-4000 \mathrm{~m}$. As this disturbance aloft moved ahead of the cold pool, the cold pool circulation and the lower-level lifting decreased (Fig. 14). This behavior is consistent with our earlier discussion of the Doppler radar observations (Fig. 6) that was consistent with a strong outflow transitioning to a bore and a weakening cold pool. The end result of this evolution was that height of the maximum vertical motion increased with time from between 1 and $3 \mathrm{~km}$ AGL to 

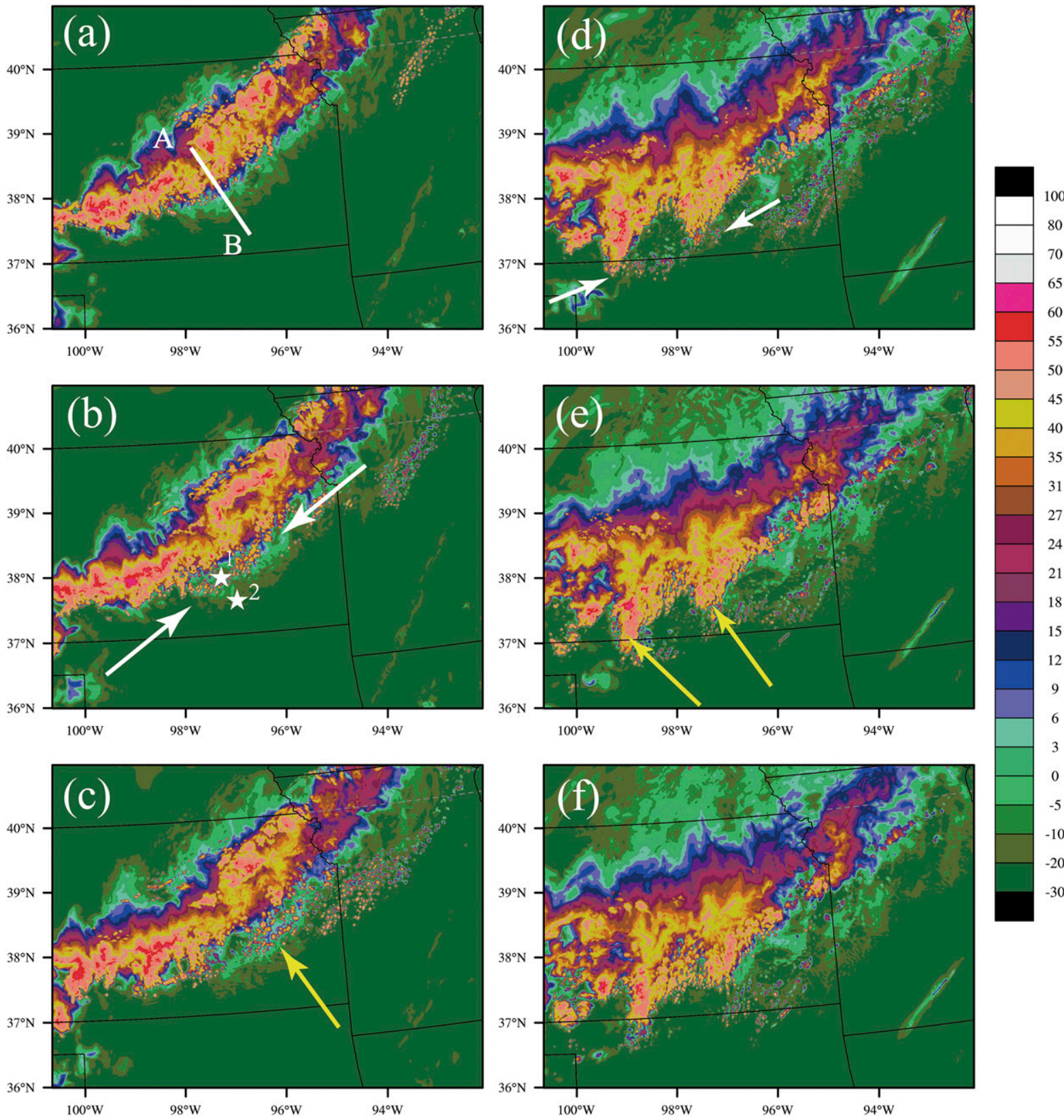

FIG. 9. Radar composite reflectivity (dBZ) generated from the WRF Model in the 1-km domain at a time when (a)-(c) first and (d)-(f) second sets of radar fine lines were generated. The color scale for the radar reflectivity is shown on the right. Times are (a) 2100, (b) 2130, (c) 2200, (d) 0000, (e) 0030, and (f) 0100 LST. White line AB represents the location of the NW-SE vertical cross sections in Figs. 12, 14, and 16. The white arrows indicate the leading edge of the two disturbances that would have been associated with radar fine lines in the observations. The yellow arrows indicate CI behind the fine lines and the stars labeled " 1 " and " 2 " indicate the location variables diagnosed in Fig. 10.

between 1.5 and $4.5 \mathrm{~km}$ AGL (Figs. 14b-e) and then weakened substantially by 2300 LST (Fig. 14g).

The examination of the potential temperature in Fig. 14 shows that the ascent was associated with an upward displacement of the elevated inversion shown earlier in the observed sounding ahead of the MCS
(Fig. 4a). This lifting of the inversion layer accounts for pronounced decrease in CIN at the leading edge of the disturbance. A second long-lasting pulse of upward motion associated with the second pulse of cold air became evident later in the lifetime of the system at $\sim 2300$ LST (Fig. 14g) and moved slowly away from the 


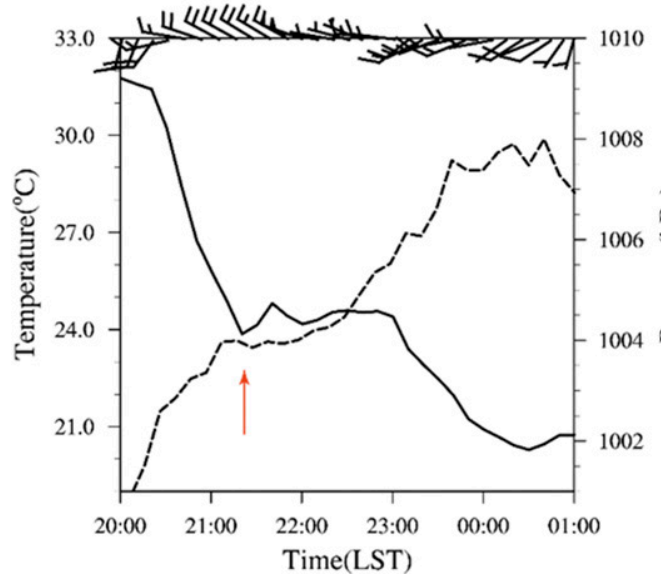

(a)

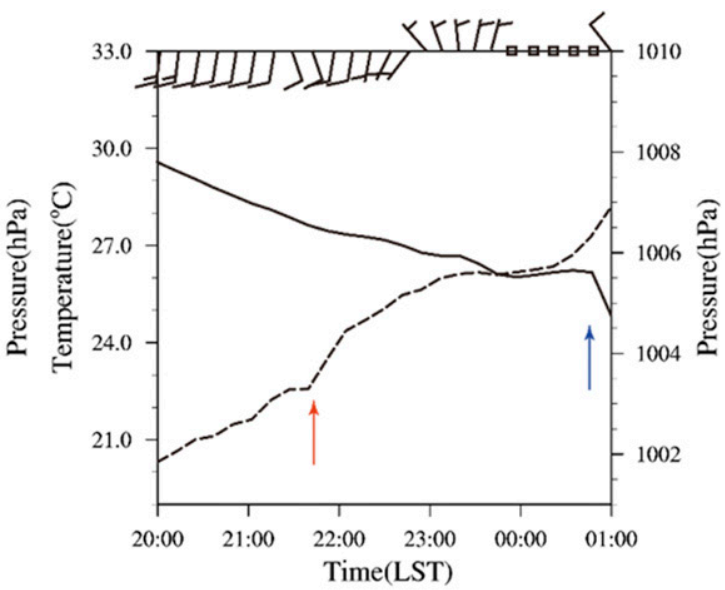

(b)

FIG. 10. Time series of temperature (solid line; ${ }^{\circ} \mathrm{C}$ ), wind barbs, and pressure (dashed line; hPa) at stations indicated by white stars in Fig. 8b. (a) Model output at the location of star "1" and (b) star "2." Note that model simulation extends only to 0100 LST.

system in a manner similar to the first pulse. This second pulse moved into the high-CAPE and reduced-CIN air mass left in the wake of the bore.

The structure of the MCS also evolved during this time. At 2000 and 2030 LST (Figs. 14a,b), the MCS is clearly evident with lifting at the leading edge of the gust front followed by convective updrafts and downdrafts. The MCS subsequently evolved (Figs. 12-14) into an organized mesoscale structure with a trailing anvil. The maximum updrafts aloft also evolved toward increasingly higher altitudes rearward from the leading edge with a sloping rear inflow beginning at $\sim 2200$ LST. The system later transitioned to a larger anvil with descent below the melting level and updrafts aloft at 0100 LST on the following day. The contours of 15 and $35 \mathrm{dBZ}$ in Fig. 14, respectively, can be roughly utilized to indicate the stratiform and convective areas along the cross section and reinforces the idea of a large trailing stratiform region behind the leading updraft (Figs. 14e,i).

In terms of convective dynamics, previous studies (e.g., French and Parker 2010; Blake et al. 2017) have shown that a favorable condition for elevated convection occurs when the positive horizontal vorticity flux due to the integrated wind shear over the layer of maximum CAPE balances the negative flux associated with the advancing cold air pool. The vertical profile of wind perpendicular to the wave (Figs. 15b,c) shows that the strong positive vertical wind shear occurs over the layer of maximum CAPE (Fig. 12). The system-relative inflow in the layer approaching the bore is also relatively strong, which, according to French and Parker (2010), is also favorable for elevated convection. Thus, the reduction in CIN by the wave and the favorable cold pool ascent were favorable for the maintenance of the MCS. Another inference that can be drawn from the vertical profile of the wind in Fig. 15 is that a critical layer where the speed of the wind matched the speed of the wave did not occur in the troposphere above the inversion. Such a critical layer would help to trap wave energy (e.g., Lindzen and Tung 1976).

\section{Dynamics of wave disturbances}

The observations and simulations show a disturbance that formed near and subsequently moved ahead of a cold outflow that modified the stability resulting in $\mathrm{CI}$ in its wake. Based on past studies, the observations, our simulation, and the characteristics of this disturbance, we hypothesize that the disturbance is a bore. However, in contrast to past studies of convectively generated bores, the maximum lifting took place in a midlevel inversion layer. We now investigation the nature of this disturbance.

\section{a. Distribution of buoyancy}

The buoyancy field $B$ was calculated following the description in Adams-Selin and Johnson (2013) and Blake et al. (2017) with

$$
B \equiv g\left[\frac{\theta^{\prime}}{\bar{\theta}}+0.61\left(q_{v}-\bar{q}_{v}\right)-q_{c}-q_{r}-q_{i}\right]
$$

where $g$ is gravitational acceleration, $\bar{\theta}$ and $\bar{q}_{v}$ represent the potential temperature and water vapor mixing ratio of the ambient air ahead of the density current, $\theta^{\prime}$ is the difference between $\theta$ and $\bar{\theta}, q_{c}$ is the cloud water mixing ratio, 

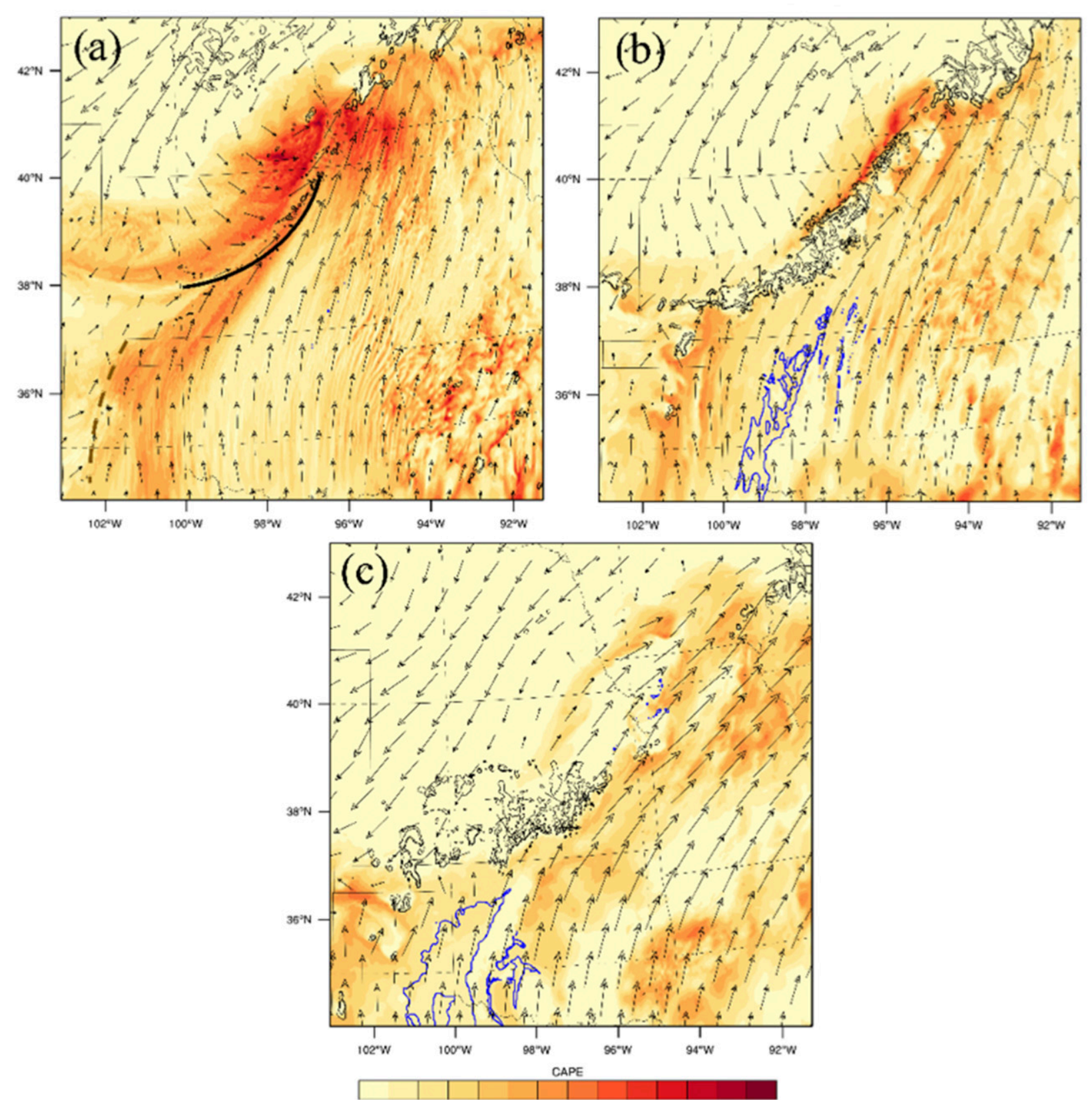

10030050070090011001300150017001900210023002500

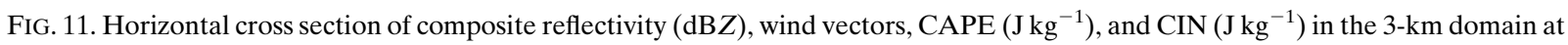
$1 \mathrm{~km}$ AGL valid at (a) 1700, (b) 2100, and (c) 0100 LST. The location of front and dryline are indicated by the black bold line and the

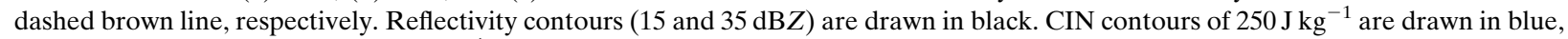
indicating the region of CIN $<250 \mathrm{~J} \mathrm{~kg}^{-1}$.

$q_{r}$ is the rainwater mixing ratio, and $q_{i}$ is the mixing ratio of frozen condensate. The terms were calculated as a function of height relative to an ambient air mass well ahead of the system calculated within the $1-\mathrm{km}$ model domain at each vertical level averaging over a $10 \mathrm{~km} \times 10 \mathrm{~km}$ box.

The variations in buoyancy ahead of the system reveal a heterogeneous environment ahead of the front
(Fig. 16) with a pronounced mesoscale area of positive buoyancy in the lowest $1000 \mathrm{~m}$ just ahead of the MCS, especially early in its lifetime from 2000 to 2100 LST (Figs. 16a-c). This positive buoyancy is consistent with the transport of warm, moist air associated with the corridor of high CAPE ahead of the front (Fig. 11) increasing the local gradient of buoyancy across the cold 

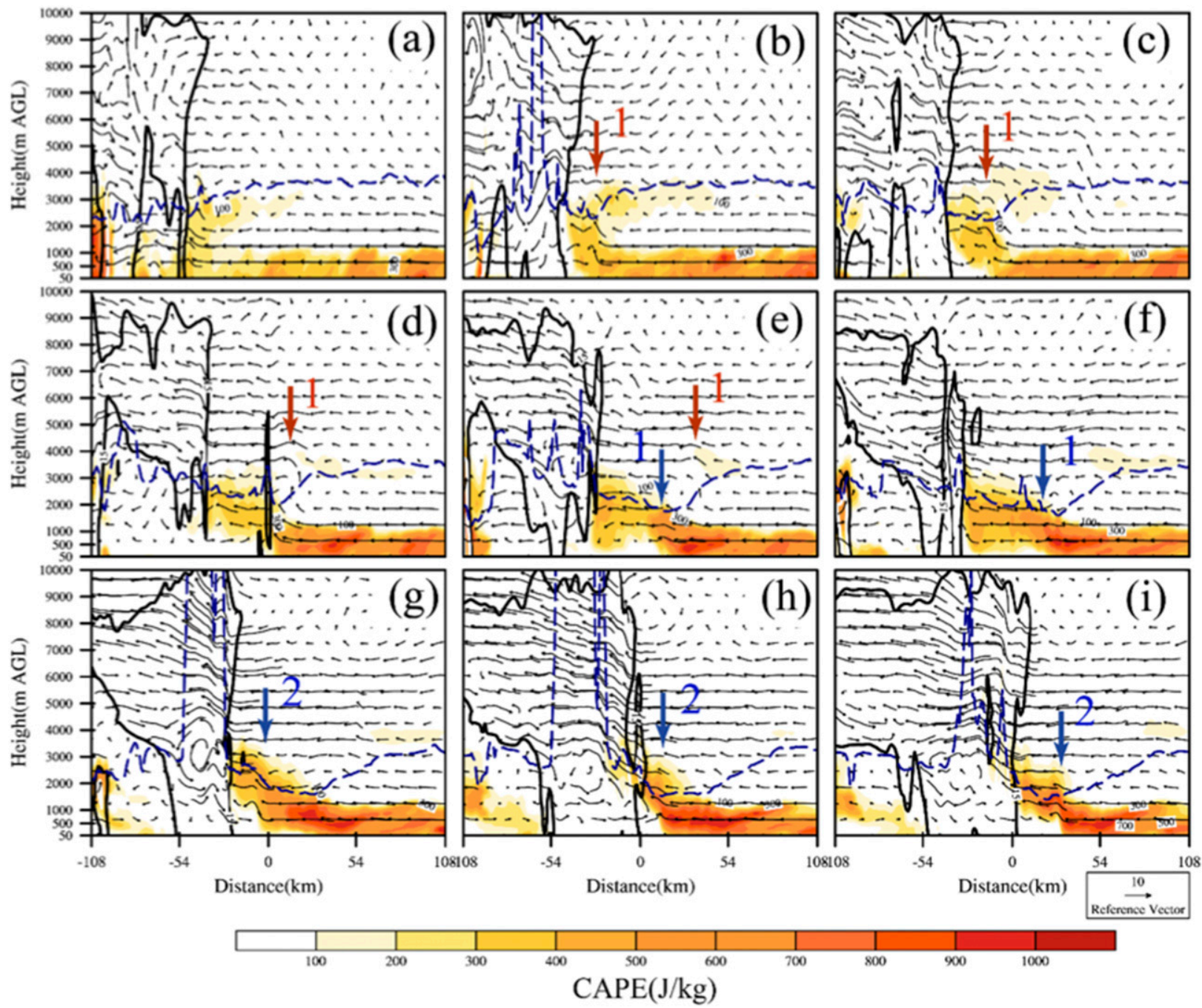
(d) 2130, (e) 2200, (f) 2230, (g) 2300, (h) 2330, and (i) 0000 LST 11 Jun. Shown are the CAPE (J kg ${ }^{-1}$; color shading), reflectivity of $15 \mathrm{dBZ}$ (bold black line), ground-relative wind vectors (wind barbs), and the LFC (bold dashed blue line). The wave disturbance labeled " 1 " with the red arrow indicates the disturbance shown in Fig. 9. The two pulses of cold air are labeled "1" and "2" with a blue arrow, with the first pulse of cold air labeled only after the wave moved away from the leading edge of the cold air. Before that time, the red arrow " 1 " also indicates the leading edge of the cold pool.

pool so that even when the negative buoyancy within the cold pool is small relative to the ambient flow well ahead of the MCS (Figs. 16a,b).

Positive buoyancy is evident within the MCS, but is generally restricted to heights above $\sim 5 \mathrm{~km}$ (Fig. 16) consistent with the nocturnal simulation of an elevated nocturnal MCS (Blake et al. 2017). This maximum in positive buoyancy within the system strengthened and descended with time so that the peak values were located at $\sim 6-7 \mathrm{~km}$ AGL after 2100 LST (Fig. 16e). The well-defined negative buoyancy within the system was generally restricted to heights below $\sim 5 \mathrm{~km}$.
The negative buoyancy below this height early in the system's lifetime (Figs. 16a,b) reflects the relatively high LFC, but also likely results from the presence of hydrometers and diabatic cooling. As the system matured, the distribution of buoyancy and the presence of sloping front-to-rear and rear-to-front flows reflects the general conceptual model of an MCS.

A cold pool in the buoyancy fields (Fig. 16), although the evolution of the cold pool was relatively complex with a slow evolution toward a stronger and deeper cold pool, is consistent with the surface data in the observations and simulations (Figs. 16h,i). Early in the system's 

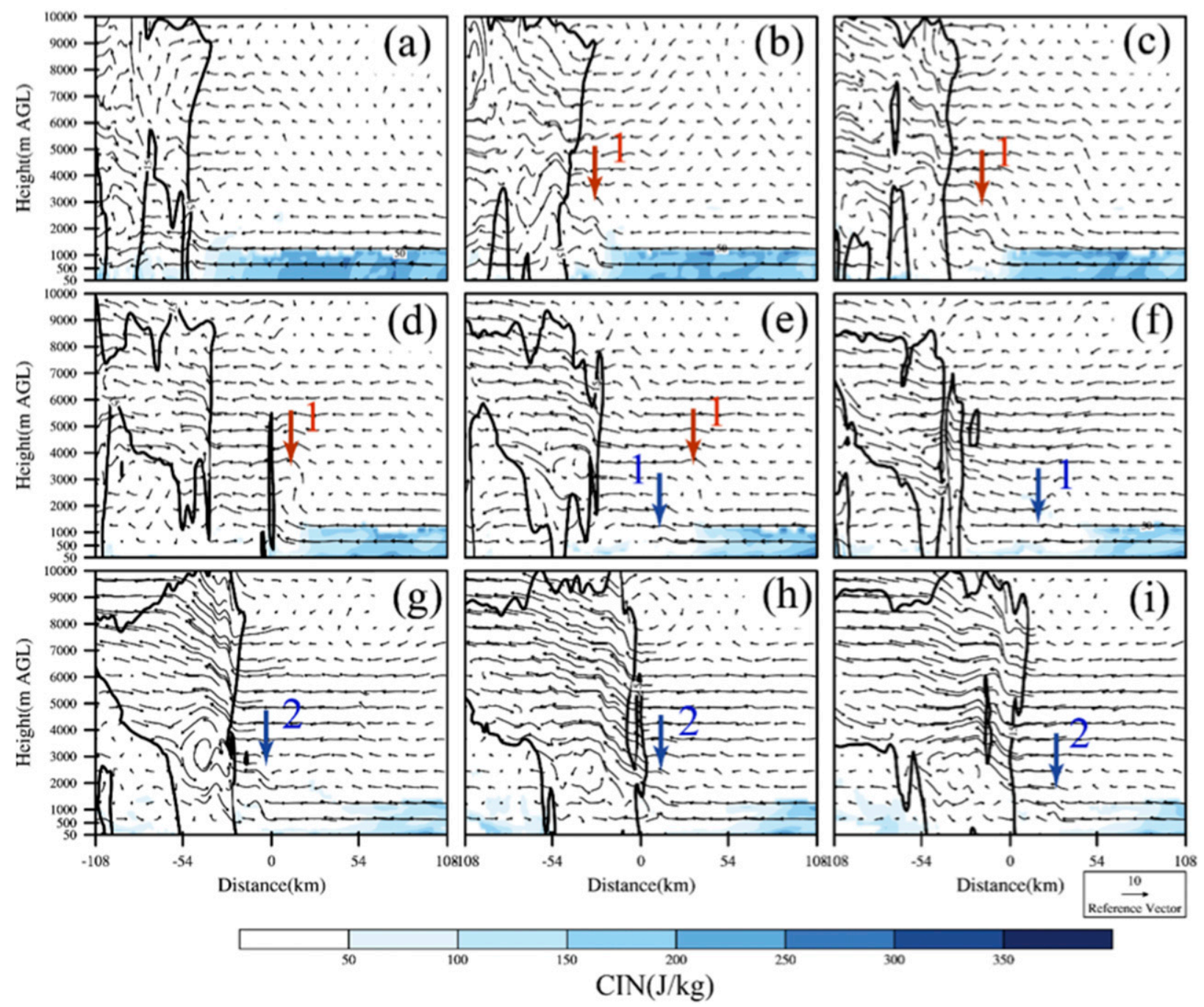

FIG. 13. As in Fig. 12, but for CIN ( $\mathrm{J} \mathrm{kg}^{-1}$; color shading), reflectivity of $15 \mathrm{dBZ}$ (bold black line), and ground-relative wind vectors (wind barbs).

lifetime, the cold pools appear as weak and transient with a tendency for the strongest negative buoyancy to sometimes be located at the lower levels on the NW edge of the domain likely associated with air behind the advancing cold front (Fig. 2).

Early in the simulation, at 2000 and 2030 LST (Figs. 16a,b), negative buoyancy occurs ahead of the MCS in the midtroposphere sloping downward from heights between 4 and $8 \mathrm{~km}$ at the SW edge of the domain to between 2 and $5 \mathrm{~km}$ closer to the MCS. As the first pulse forms and moves ahead of the system, negative buoyancy occurs at heights between $\sim 2$ and $4 \mathrm{~km}$ with positive buoyancy aloft (Figs. 16c-e). The negative (positive) buoyancy is consistent with ascent (descent) and cooling (warming) associated with the disturbance. The dramatic creation of negative buoyancy between $\sim 1.5$ and $\sim 3.5 \mathrm{~km}$ is consistent with cooling due to the lifting of the inversion and the reducing the relatively large CIN in the environment (Fig. 4a). The modest increase in CAPE discussed earlier is consistent with the negative buoyancy in the lower levels overcoming the increase of CAPE that would be associated with the warming aloft.

Additional insight provided by the pressure perturbation field in Fig. 16 reveals a pressure rise of $\sim 1.0 \mathrm{hPa}$ within and below disturbances 1 and 2 consistent with the ascent and cooling associated with this propagating layer of negative buoyancy. The pressure contours in Figs. 16c-f also show a pressure surge at leading edge of the MCS consistent with a bore generated by the cold pool much later in the life of the system as observed. The pressure field also suggests the presence of other 


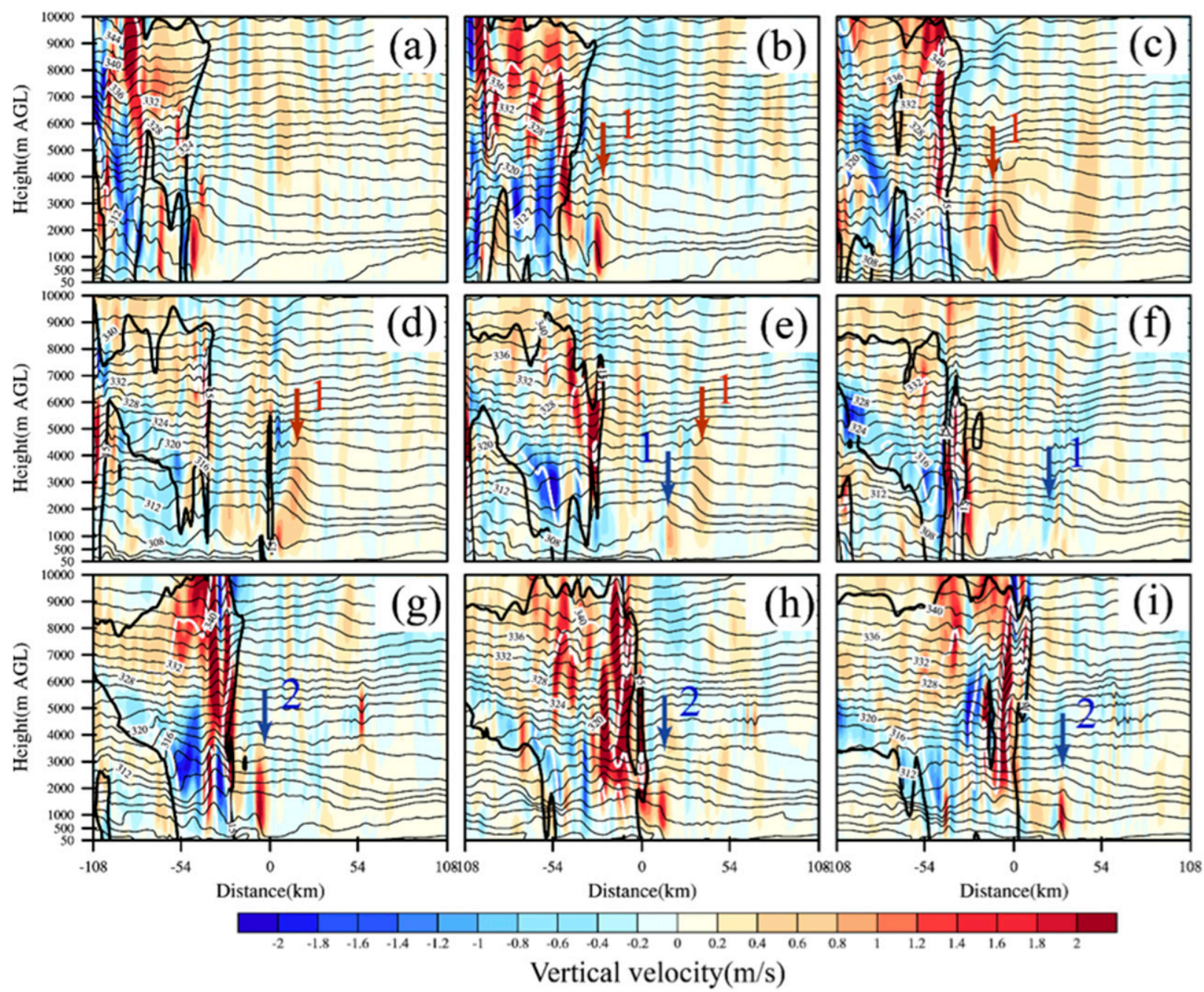

FIG. 14. As in Fig. 12, but for vertical velocity ( $\mathrm{m} \mathrm{s}^{-1}$; color shading), reflectivity of 15 (bold black line) and $35 \mathrm{dBZ}$ (white line), and potential temperature (thin black contours).

transient disturbances ahead of the main pulse. The vertical distribution of buoyancy distribution with cooling and negative buoyancy in the lower troposphere due to ascent and descent and warming in the upper troposphere is also consistent with the expectations of an $n=2$ mode of long-period gravity waves with ascent topped by descent. The dramatic reduction in CIN, the lowering of the LFC and slight increase CAPE with the updraft surge (indicated by red arrow " 1 " in this paper) are also consistent with past studies of the impact of convectively generated long-period gravity waves (e.g., Lane 2011; Adams-Selin and Johnson 2013).

The possibility that the disturbance is essentially an $n=2$ mode gravity wave was explored through examining the vertical profile of vertical motions associated with the disturbance (Fig. 17) during the period from 2100 to 2200 LST when the wave formed and moved away from the first cold surge. This analysis suggests that initially at 2100 LST (Fig. 17a) the ascent was shallow $(\sim 1.4 \mathrm{~km}$ in height), strong (area average approaching $1 \mathrm{~m} \mathrm{~s}^{-1}$ ) and dominating by lifting at the leading edge of the cold pool. Subsequently at 2130 and 2200 LST (Figs. 17b,c), the strongest vertical motions were located at a height of $\sim 3 \mathrm{~km}$ and remained strong with area-averaged ascent of nearly $0.6 \mathrm{~m} \mathrm{~s}^{-1}$. Weak descent was evident in the upper troposphere during this time (Figs. 17a-c). The profile of ascent in the lower troposphere topped by descent was explored through repeating the area average for a larger $40 \mathrm{~km} \times 40 \mathrm{~km}$ region ahead of the MCS. This calculation, shown in Fig. $17 \mathrm{~d}$ for 2130 LST, reveals that the larger-scale environment better reflects a structure of ascent and descent more consistent a deep troposphere gravity wave. From the vertical cross sections shown earlier and the 

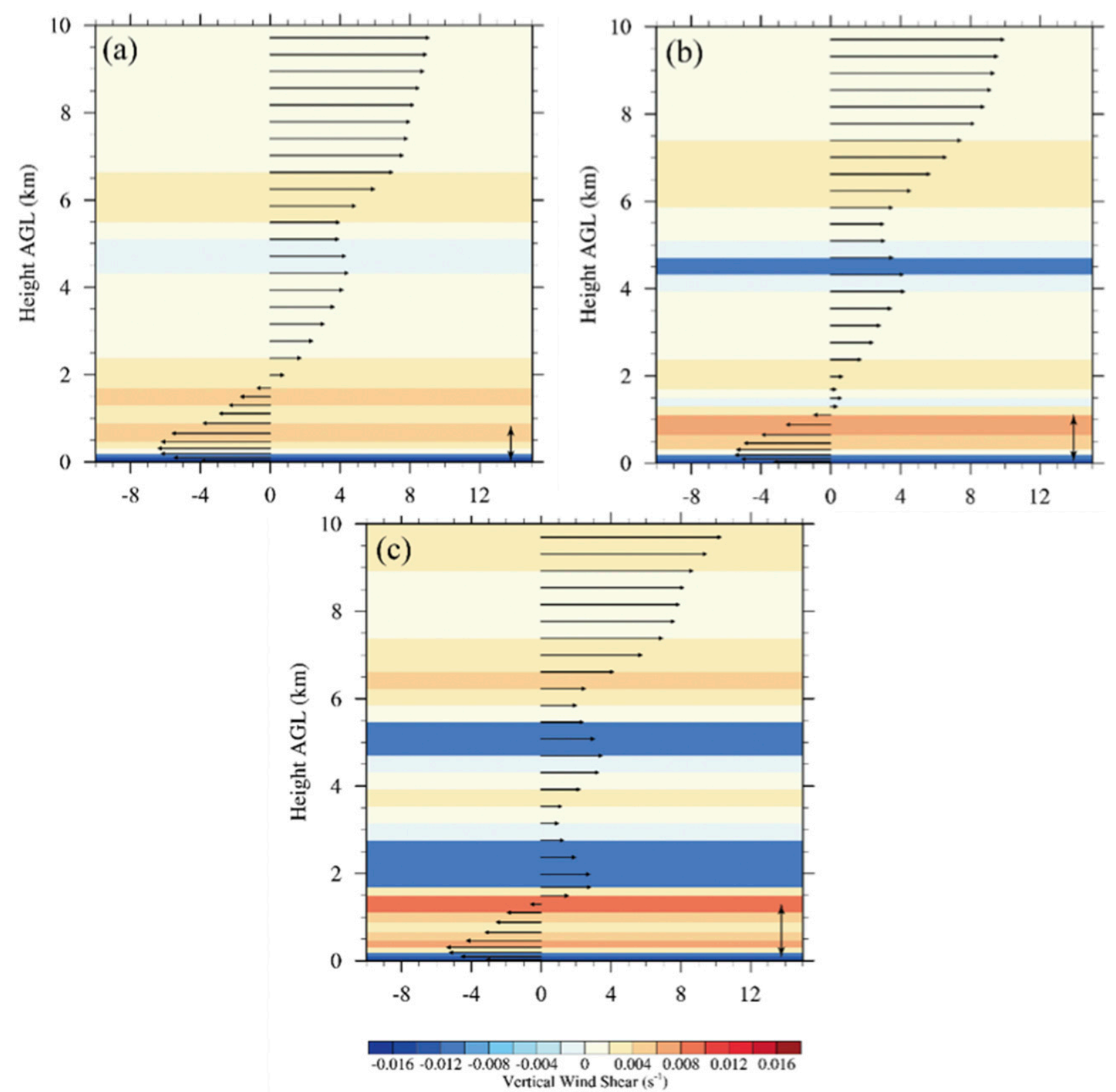

FIG. 15. Vertical profile of the horizontal wind speed $\left(\mathrm{m} \mathrm{s}^{-1}\right)$ of the ambient flow in the 1-km domain for NW-SE orientation at (a) 2000 LST (30 min before the bore's generation), (b) 2100 LST (at the bore's generation), and (c) 2230 LST (near the time of the bore's dissipation). The vertical wind shear $\left(\mathrm{s}^{-1}\right)$ is color contoured in the background.

area-averaged vertical motions, we hypothesize that the environment is characterized both by a strong wave disturbance in the inversion aloft and deep tropospheric gravity waves. The wave responses in the simulation are complex and varied resembling the more complex structures in Stephan et al. (2016) rather than just a clearly defined long-period gravity wave modes (i.e., $n=$ $1,2,3)$. The strong ascent in the inversion layer (Figs. 17b,c) fits neither the concept of a bore generated within the SBL nor a long-period wave. Subsidence in the upper troposphere does tend to increase with time (Figs. 17b,c) consistent with an $n=2$ mode.

\section{$b$. Linear wave theory and trapping of wave energy}

From the analysis thus far, we can state that the disturbance within the inversions lasted for $\sim 2 \mathrm{~h}$ and propagated at an estimated speed of $13.8 \mathrm{~m} \mathrm{~s}^{-1}$; faster than the leading edge of the MCS and the surging cold pools. This simulated velocity is quite close to the observed speed of fine line of $13.5 \mathrm{~m} \mathrm{~s}^{-1}$ as estimated from 

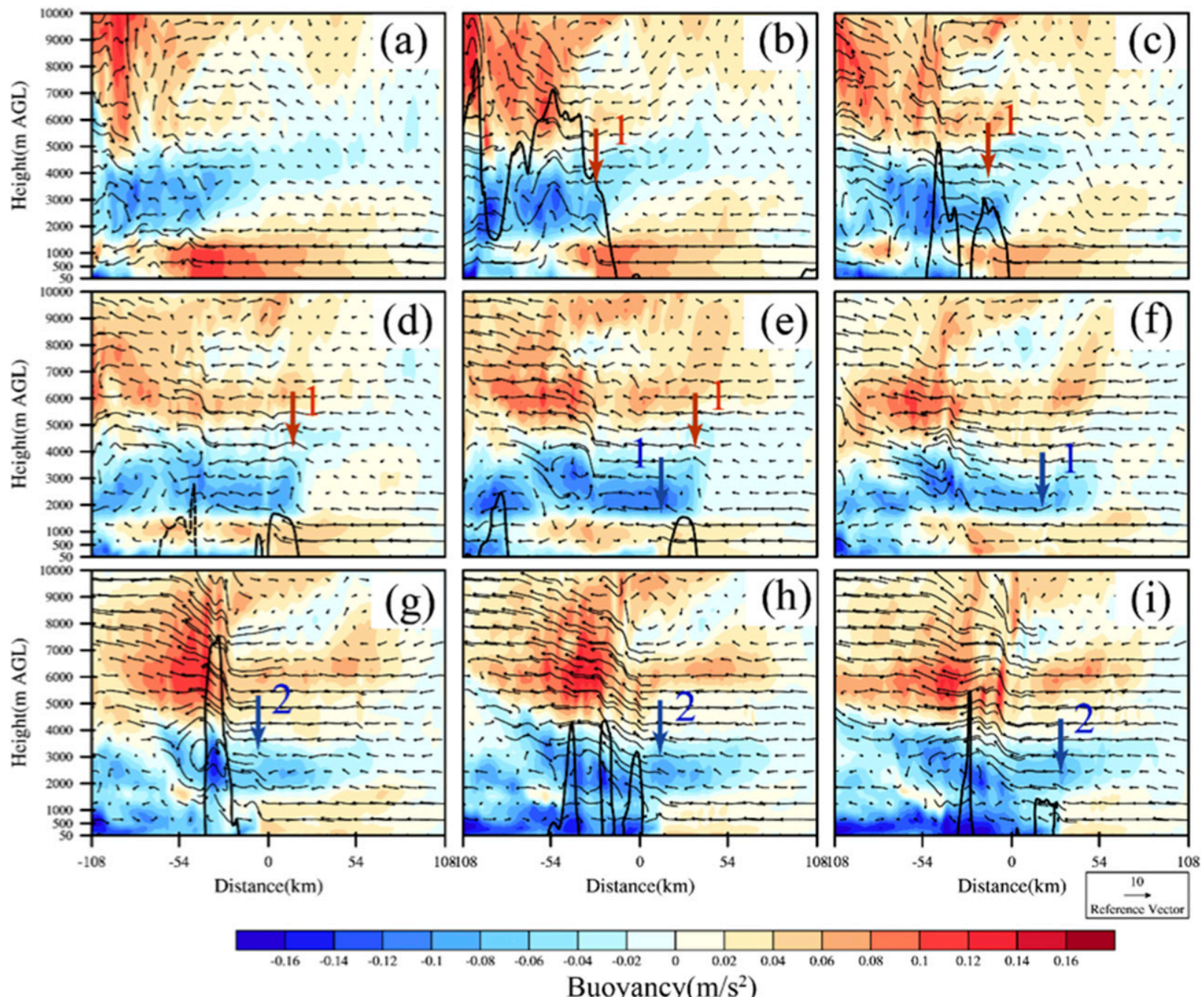

Buoyancy $\left(\mathrm{m} / \mathrm{s}^{2}\right)$

FIG. 16. As in Fig. 12, but for buoyancy ( $\mathrm{m} \mathrm{s}^{-2}$; color shading), ground-relative wind vectors (wind barbs), and pressure perturbation [dashed black line: $-1 \mathrm{hPa}(30 \mathrm{~min})^{-1}$; solid black line: $+1 \mathrm{hPa}(30 \mathrm{~min})^{-1}$ ].

the VNX radar between 2130 and 2200 LST providing additional confidence that the simulated disturbance in the inversion is likely representing the observed disturbance. However, the inversion itself is not likely to trap wave energy (e.g., Lindzen and Tung 1976) and a critical layer did not exist in the layers above the duct so that another mechanism is needed to trap the vertical propagation of the wave energy. To investigate the trapping mechanism, we calculated the Scorer parameter for times corresponding to the generation and propagation of the wave. At the risk of oversimplification, a layer of positive Scorer parameter $l^{2}$ topped by a negative layer above the positive layer will establish a wave duct and allow the wave energy to be trapped through the internal reflection (i.e., Scorer 1949; Crook 1988). The Scorer parameter is defined as

$$
l^{2}=\frac{N^{2}}{\left(U-C_{b}\right)^{2}}-\frac{\partial^{2} U / \partial z^{2}}{U-C_{b}},
$$

with the first term of Eq. (2) including the static stability, with $N^{2}$ the square of the Brunt-Väisälä frequency, $U$ the wind speed in the direction of motion of the bore, and $C_{b}$ the speed of the wave. The second term includes the effects of wind profile "curvature."

The speed $13.8 \mathrm{~m} \mathrm{~s}^{-1}$ in the direction of the cross section was used to calculate the Scorer parameter. Several features are evident in $l^{2}$ (Fig. 18a), such as the sharp decrease below $0.5 \mathrm{~km}$ AGL, which is associated with the small-scale fluctuations in the curvature of the wind profile (Martin and Johnson 2008). Two potential wave ducts and trapping layers are also evident after 2030 LST. One wave duct is evident below $\sim 1.2 \mathrm{~km}$ that 

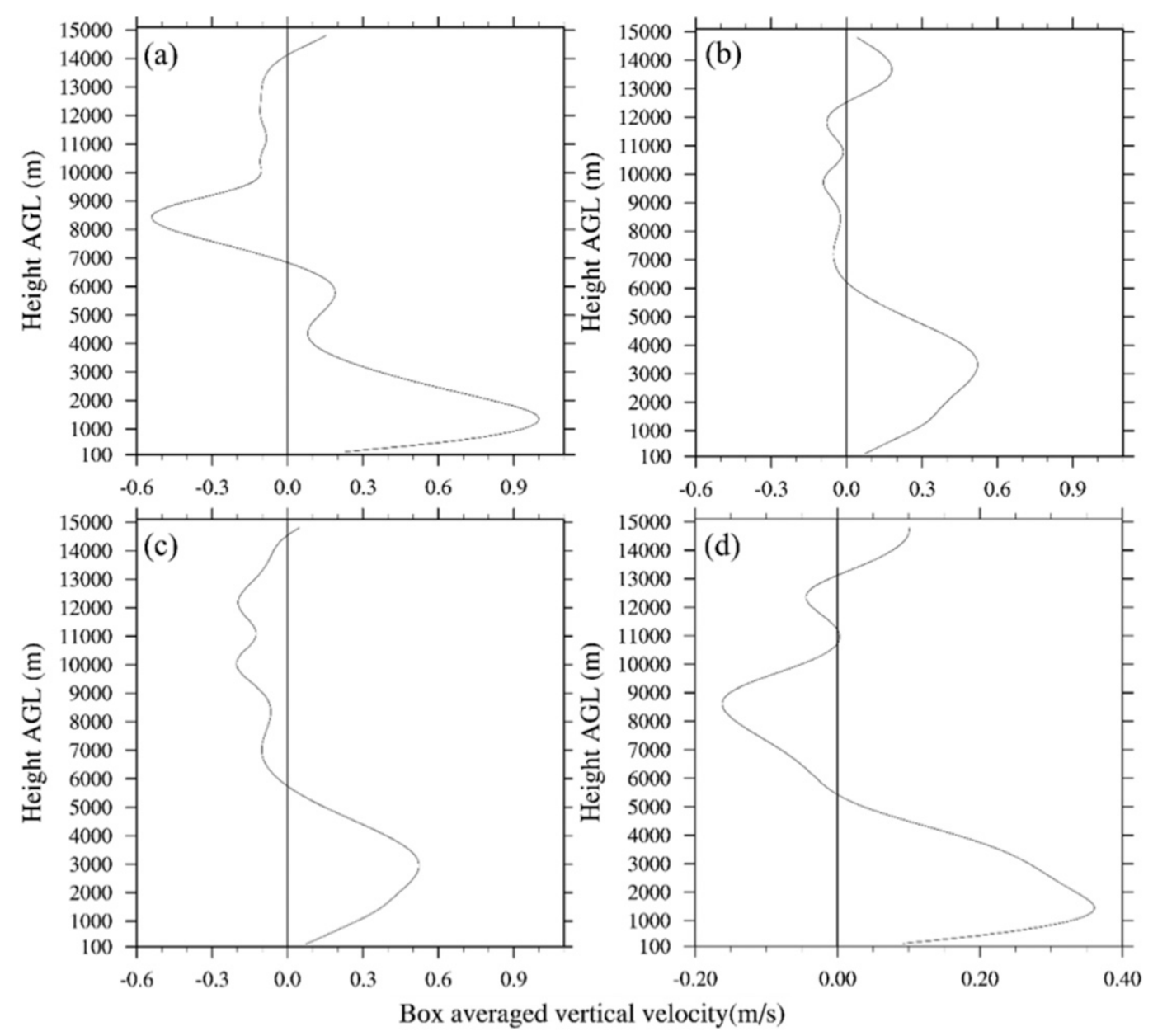

FIG. 17. (a) Vertical profile of vertical velocity from the simulation averaged over a $10 \mathrm{~km} \times 10 \mathrm{~km}$ area centered at the leading edge of the first surge of cold air at 2100 LST. (b) As in (a), but centered on the wave propagating away from the cold pool at 2130 LST. (c) As in (b), but at 2200 LST. (d) As in (b), but for a $40 \mathrm{~km} \times 40 \mathrm{~km}$ area ahead of the system.

is topped by a layer of negative reminiscent of the lowlevel wave duct in the nocturnal environment associated with "curvature" of the vertical wind profile (i.e., Haghi et al. 2017). A second duct topped by a trapping layer was also evident between $\sim 1.7$ and $4 \mathrm{~km}$ in height with the curvature term creating a favorable Scorer profile aloft. Since disturbed synoptic environments, such as this event, would likely be associated with greater vertical shear aloft, the synoptic disturbance likely plays a role in wave trapping. The correspondence between the top of the wave duct as defined by the Scorer parameter and the peak vertical motion (both near $4 \mathrm{~km}$ ) supports the argument for a wave within the inversion. The Haghi et al. (2017) study also found cases with secondary wave ducts aloft. However, the negative values of $l^{2}$ aloft are quite modest, at best, and whether the wave is trapped will depend on the wave's horizontal wavenumber (e.g., Haghi et al. 2017). The first pulse did show evidence of vertical propagation and weak trapping as the wave was difficult to track after $\sim 90$ min (see Figs. 14b-e).

\section{c. Long-period gravity waves}

As discussed earlier, the observed buoyancy field is consistent with an $n=2$ long-period gravity waves residing within the tropopause. The speed of these waves is given by Nicholls et al. (1991):

$$
c=\frac{N H}{n \pi},
$$

where $N$ is the Brunt-Väisälä frequency, $H$ is the vertical depth of the atmosphere, and $n$ is the vertical model of the heating profile. In the region of interest, $n=1$ gravity waves have been observed in association with deep convection as Bryan and Parker (2010) found buoyancy and pressure patterns in conjunction with an 

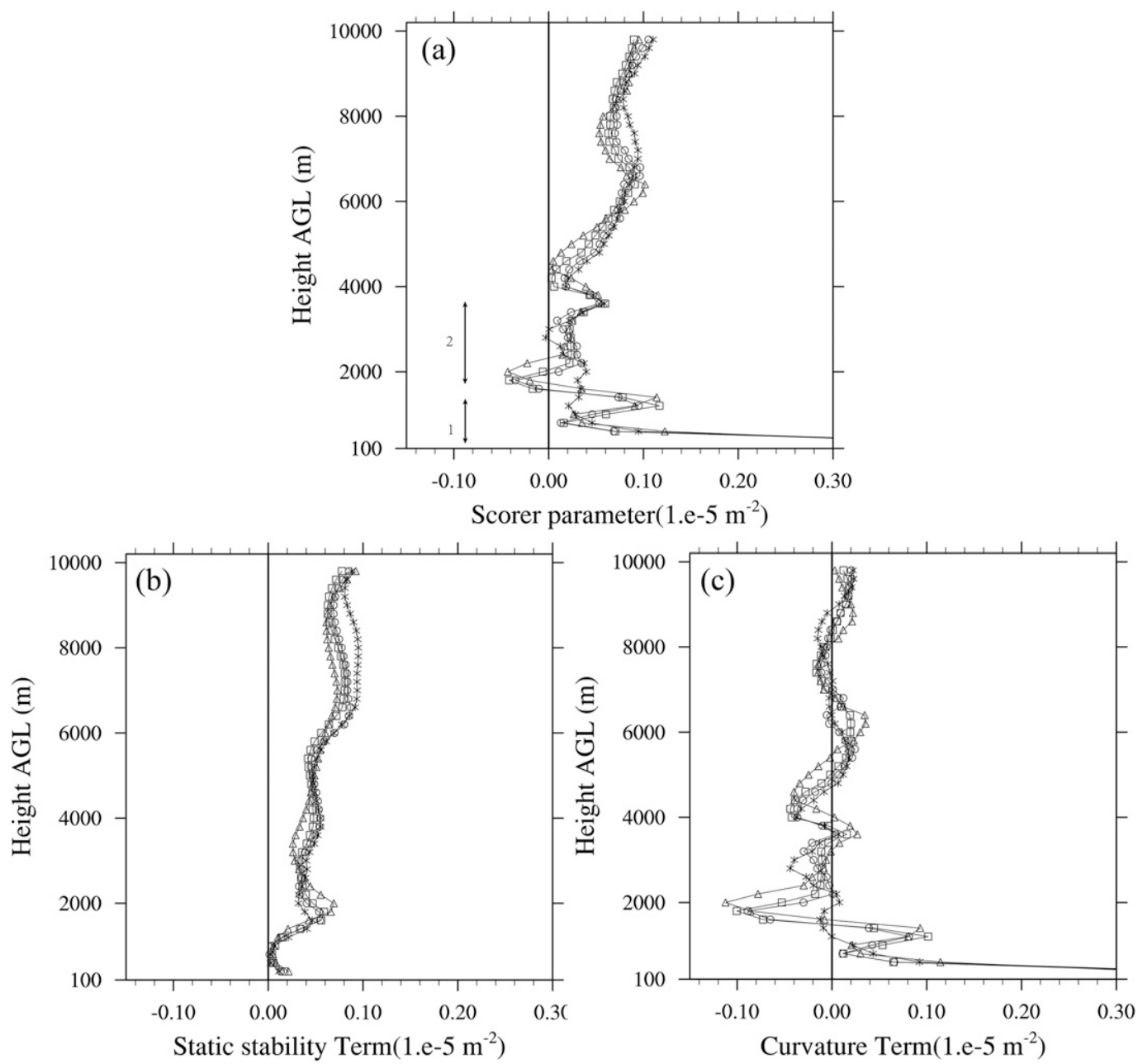

FIG. 18. (a) The Scorer parameter and the so-called (b) static stability and (c) curvature terms $\left(10^{-5} \mathrm{~m}^{-2}\right)$ as a function of height at 2100 (asterisks), 2130 (hollow circles), 2200 (hollow squares), and 2230 (triangles) LST for cross-section AB. The vertical black line represents a Scorer parameter of $0 \mathrm{~m}^{-2}$. Wave ducts are indicated by arrows 1 and 2.

Oklahoma squall line that appeared to be associated with this mode. In addition, Adams-Selin and Johnson (2010) observed that the surface pressure and temperature patterns associated with an Oklahoma bow echo that appeared to be due to $n=1$ and 2 gravity waves. The lower-tropospheric lifting associated with the $n=2$ modes is an effective at removing CIN as was observed in the model and suspected in the observations from CI taking place behind the disturbances. Based on model fields shown in Figs. 13-16, the wave speed from Eq. (3) is $16.4 \mathrm{~m} \mathrm{~s}^{-1}$ (given $N$ the average value of the layer wave transport in $\left.\sim 1.06 \times 10^{-4}, H=10 \mathrm{~km}, n=2\right)$. The prediction is relatively close to the speeds of $\sim 13.8 \mathrm{~m} \mathrm{~s}^{-1}$ in the simulations and $13.5 \mathrm{~m} \mathrm{~s}^{-1}$ in the observed system so that this type of long-period gravity wave may be present.

Observational studies have suggested that longperiod gravity waves generated by MCS and propagate ahead of the system and initiate convection (e.g., Uccelini 1975). Idealized simulations have provided further understanding into the nature of these gravity waves. For example, Stephan et al. (2016) found that deep, intense latent heat release within the precipitation systems is the key forcing mechanism for the observed gravity waves, which may potentially remotely interact with and enhance active precipitation. Previous work by Pandya and Durran (1996) show that the distribution of diabatic heating and cooling can force these waves. The lifting of the gravity wave could also cool and moisten the lower troposphere to provide more favorable condition for CI (Adams-Selin and Johnson 2013). These idealized models (Pandya and Durran1996; Stephan et al. 2016) appear to replicate aspects of the observed gravity wave and resemble the observed circulations. 


\section{Idealized simulation}

While we note that the movement of the disturbance in the observations and the simulation was not a close match to an $n=2$ mode gravity wave, the results thus far suggest the possibility that the disturbance was either an elevated bore or an $n=2$ mode gravity wave. In an attempt to clarify the mechanism for the disturbance in the inversion, we examined flow over a 2D bell-shaped mountain in an idealized WRF simulation. Since the disturbance originated near the leading edge of the cold pool, we selected this type of idealized experiment as the mountain would act as a barrier to the inflow similar to lifting by the cold pool near the surface. The intent of this simulation was to further isolate the mechanism for the observed disturbance. For example, the idealized simulations were dry in that no cloud fields or precipitation were generated so that buoyancy gradients resulting from diabatic heating would not be a source of wave generation. Hence, these idealized simulations essentially eliminate the possibility of $n=2$ mode waves driven by diabatic heating. While adiabatic warming and cooling could still be argued as relevant, this experimental design will also not generate circulations driven by buoyancy gradients in the initial conditions, such as would occur with idealized simulations with cold pools, such as "dam break" simulations.

\section{a. Simulations}

Flow over an obstacle has long been utilized to predict and understand the generation of atmospheric bores with favorable results beginning with Rottman and Simpson (1989) and supported by subsequent studies (e.g., Koch and Clark 1999; Koch et al. 2008a,b; Coleman and Knupp 2011; Blake et al. 2017; Haghi et al. 2017; Chasteen et al. 2019). Simulations with different mountain heights and stability profiles were also conducted to further substantiate our conclusions.

Our control simulation was initialized with the original sounding at the southeast end of cross section at 1955 LST with a mountain height of $\sim 1500 \mathrm{~m}$ in order to represent a cold pool depth of over $1 \mathrm{~km}$ with a deeper density current head. This sounding had a weakly stable, near-neutral PBL and an inversion layer aloft around 900-2000 m AGL. The flow response to the mountain included an elevated transient response aloft between 5 and $8 \mathrm{~km}$ that was evident at $\sim 60$ min into the simulation (Fig. 18b) with some characteristics similar to an elevated transient response in the earlier simulations (Fig. 14c). A lower-level wave response later formed that slowly moved upstream away from the mountain in the layer between 1 and $3 \mathrm{~km}$ (Figs. 19c-f). The height and movement of the disturbance $\left(\sim 13.9 \mathrm{~m} \mathrm{~s}^{-1}\right)$ is close to the speed of the first pulse in the observations and the simulation $\left(\sim 13.8 \mathrm{~m} \mathrm{~s}^{-1}\right)$. The vertical motion maximum, however, was located just above $2 \mathrm{~km}$, which is significantly lower than in the simulation. This difference is likely associated with our selection of an ambient environment well ahead of the MCS and the upward slope of the inversion at distances closer to the front (e.g., see potential temperature contours in Fig. 14).

Idealized simulations with different sounding profiles and mountain height were also conducted to explore the hypothesis that the wave in the idealized simulation formed since the cold pool is sufficiently deep so that the flow over the cold pool lifted the inversion layer aloft and initiated a propagating wave. The results show that shallow cold pools (e.g., $1 \mathrm{~km}$ and less) will not induce a wave response. Since the simulation does not include any diabatic heating, the disturbance that propagates upstream is not associated with the distribution of diabatic warming and cooling within the system as might be expected for the "typical" generation of an $n=2$ mode wave. The pattern of fixed subsidence aloft induced by the obstacle is also similar to the warming and subsidence observed in the full-physics simulations that was previously attributed to the $n=2$ mode wave illustrating the difficulty attributing cause and effect in studies of waves and MCSs.

Simulations with a neutral boundary layer (Fig. 20) appear nearly identical to the control simulation, but with a slightly weaker wave response (see comparison between Figs. 19e and 20e). Hence, the stable boundary layer does not play a significant role in the generation of this wave, in contrast to past studies of nocturnal bores in this environment (e.g., Haghi et al. 2019). The finding that this upstream disturbance can occur with a neutral boundary layer suggests that this mechanism may occur during the day or night under appropriate conditions. The previously mentioned past studies of bores in this region were typically associated with nocturnal MCS. The generation of this wave with a neutral boundary layer and an inversion aloft is highly relevant to the conditions over the Great Plains due to the frequent presence of an elevated capping inversion.

\section{b. Hydraulic theory}

In this section, we will use the context of hydraulic theory to determine the causes of this elevated disturbance. Under the framework of a two-layer, inviscid flow that has been shown to match the idealized orographic flow regime and observations (e.g., Rottman and Simpson 1989; Koch et al. 1991; Haghi et al. 2017), the following flow regimes are possible: supercritical, partial blocking, subcritical, complete blocking (Fig. 21). Bores will be initiated in the partially or completely blocked 

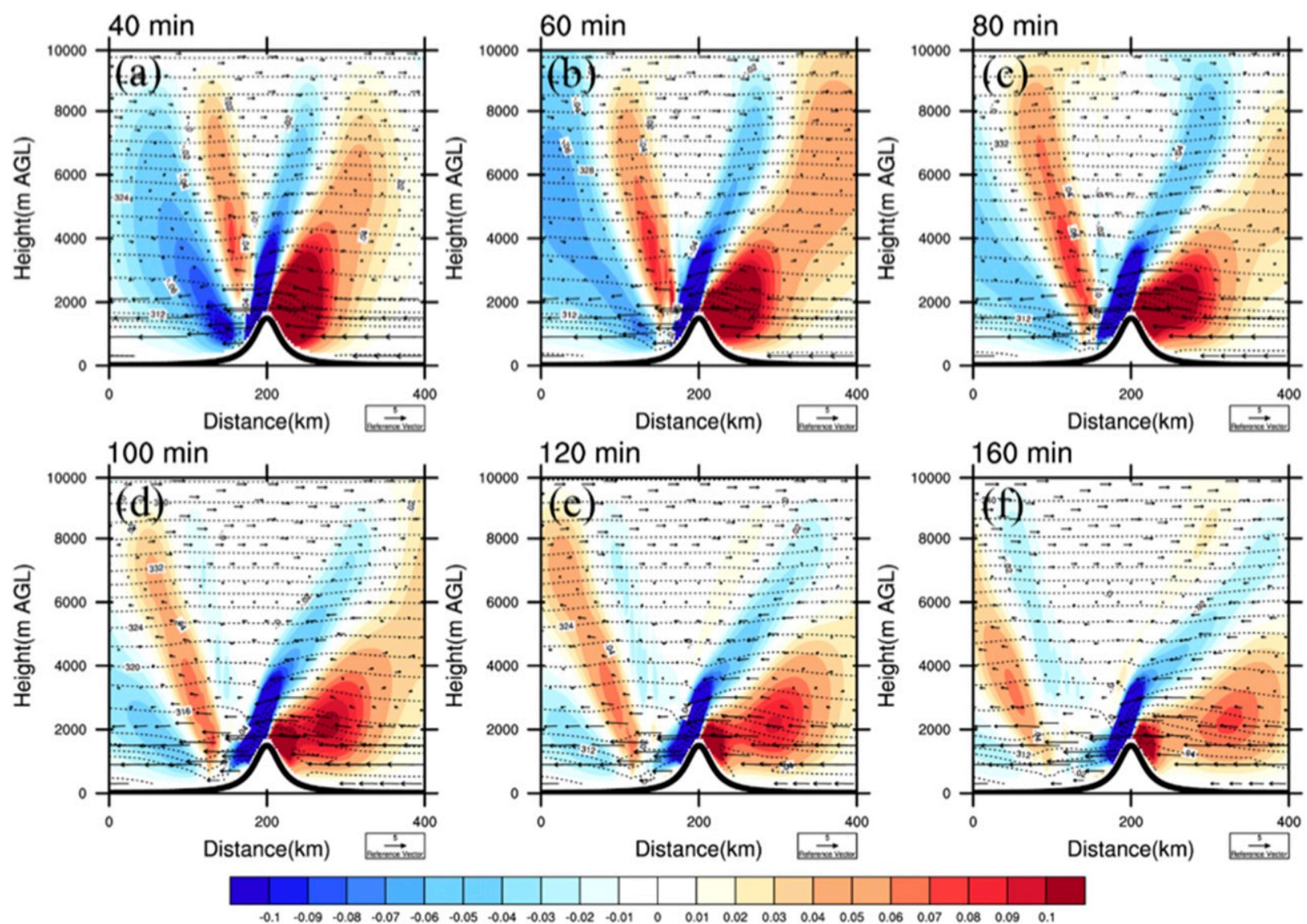

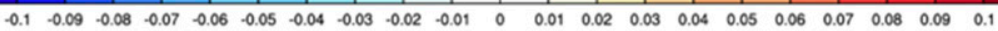

Vertical velocity $(\mathrm{m} / \mathrm{s})$

FIG. 19. Time series of idealized simulations of a weakly stable low level, including vertical velocity ( $\mathrm{m} \mathrm{s}^{-1}$; color shading), wind vectors (wind barbs), and potential temperature (dashed contours)

flow regimes. In this framework, the possible timeindependent solutions of the shallow water equations are determined by two nondimensional parameters $D_{0}$ and $F_{r}$ (Long 1955; Houghton and Kasahara 1968; Baines 1984; Rottman and Simpson 1989).

In this two-layer model, a weak or neutral stability layer occurs below the inversion and the second layer is layer above the inversion. The stability difference between the two layers is defined by the inversion. We use a modified form of the equations derived from Haghi et al. (2017) given as

$$
\begin{aligned}
& F_{r}=\frac{\left(U_{\mathrm{cp}}-U_{a}\right)}{C_{\mathrm{gw}}}=\frac{\left(U_{\mathrm{cp}}-U_{a}\right)}{\sqrt{g\left(\frac{\Delta \theta_{\mathrm{vw}}}{\theta_{\mathrm{vw}}}\right) h_{0}}}, \\
& D_{0}=h / h_{0},
\end{aligned}
$$

where $D_{0}$ is a nondimensional height given by the ratio of $h$ (depth of cold pool) and $h_{0}$ (depth of the inversion layer). $F_{r}$ is the Froude number, $U_{\mathrm{cp}}$ the cold pool speed, $C_{\mathrm{gw}}$ the speed of a gravity wave, $g$ is the acceleration due to gravity, $U_{a}$ is the mean horizontal velocity in the layer below the inversion layer, $\theta_{\mathrm{vw}}$ is the virtual potential temperature at bottom of inversion layer, and $\Delta \theta_{\mathrm{vw}}$ is the difference in $\theta_{\mathrm{vw}}$ from top to the bottom of the inversion layer.

Depths of cold pool in the full-physics simulation and heights of bell-shaped mountain in the idealized experiments were used for calculating the flow regime using the previously mentioned sounding profile at the southeast end of the cross section at 1930 and 2030 LST. The inversion-layer base was defined as the depth where layers of $d \theta / d z$ first increase above $0.003 \mathrm{~K} \mathrm{~m}^{-1}$ continuously. Due to the weaker density current and weaker bore, $d \theta / d z$ is set to be smaller compared to that set in Blake et al. (2017) of $0.005 \mathrm{~K} \mathrm{~m}^{-1}$. Table 2 and Fig. 21 provides results that show a partially blocked flow typically occurs in most situations. The exceptions are when the depth of density current is insufficient resulting in a 

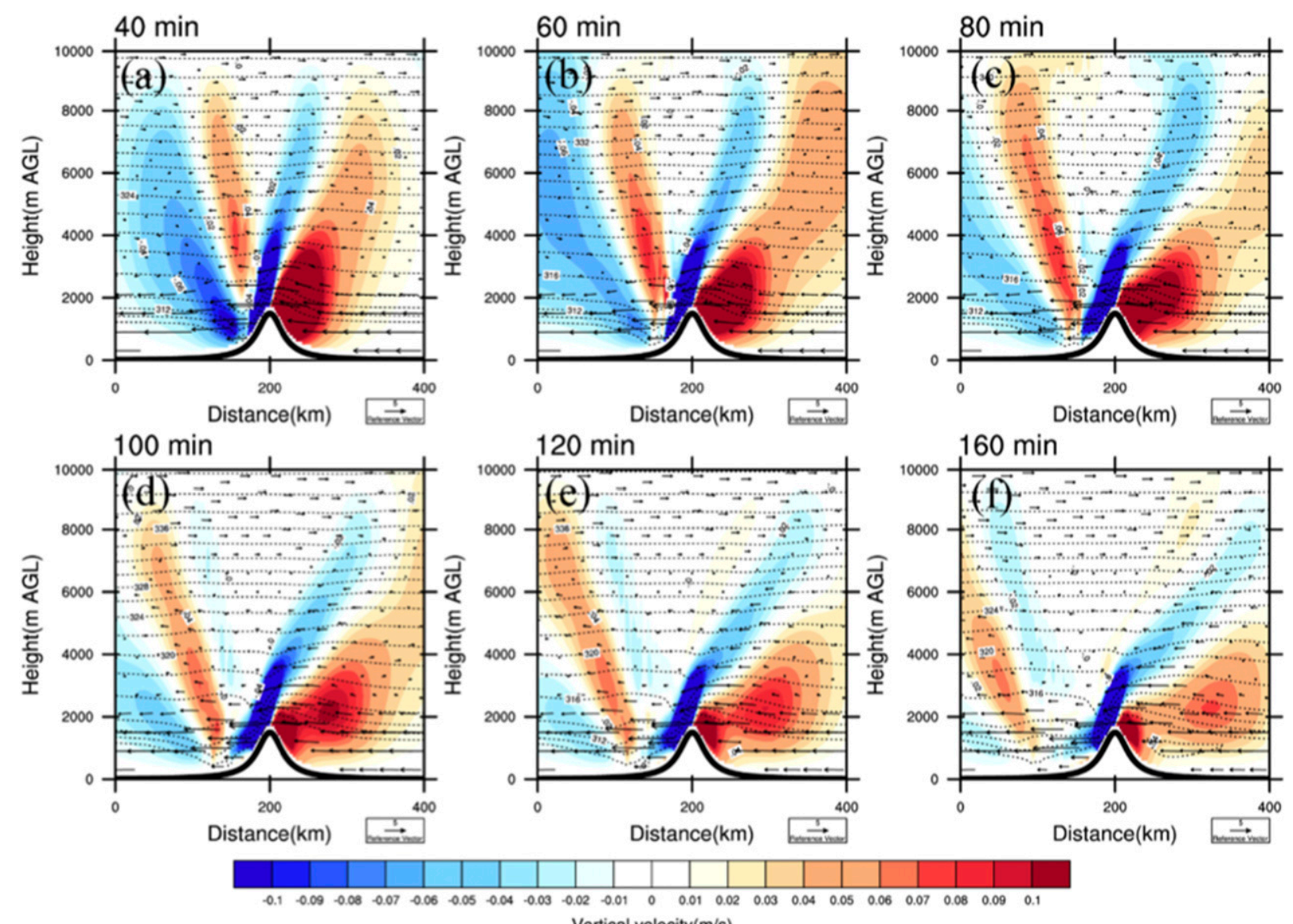

$\begin{array}{lllllllllllllllllllll}-0.1 & -0.09 & -0.08 & -0.07 & -0.06 & -0.05 & -0.04 & -0.03 & -0.02 & -0.01 & 0 & 0.01 & 0.02 & 0.03 & 0.04 & 0.05 & 0.06 & 0.07 & 0.08 & 0.09 & 0.1\end{array}$

Vertical velocity $(\mathrm{m} / \mathrm{s})$

FIG. 20. As in Fig. 19, but for a simulation with a neutral layer below the inversion.

supercritical partially blocked regime where the presence of a bore depends on how the experiment is initialized (e.g., Rottman and Simpson 1989) or in one case a supercritical flow where a bore would not be generated. These results, consistent with the idealized simulation and the full-physics model, suggest that the interaction between the ambient environment and the cold pool will generate a bore aloft provided that the cold pool is sufficiently deep. A conceptual model shown earlier (Fig. 1) summarizes the comparison between elevated bores and those initiated with a stable nocturnal boundary layer.

\section{Conclusions}

The challenges of understanding and predicting nocturnal convection over the Great Plains is outlined in Geerts et al. (2017), while the current state of knowledge of atmospheric bores and gravity waves that are often associated with nocturnal MCS can be found in Haghi et al. (2019). In this case, an observed and simulated disturbance that formed near and propagating away from a convectively generated cold pool had the characteristics of a bore (strong pressure rise at the surface without a corresponding decrease in the surface temperatures). In contrast to the findings summarized in Haghi et al. (2019) that discuss bores within and just above the SBL, our study suggests that an "elevated" bore developed when a capping layer aloft was lifted by a sufficiently deep cold pool producing a partially blocked flow regime. This bore created a more favorable convective environment through lifting of the capping layer with widespread $\mathrm{CI}$ in its wake.

The concept of an elevated bore was supported by idealized experiments and theory. Idealized simulations show that an elevated bore can form in the presence of a well-mixed diurnal boundary layer. Given that capping inversions are common over the Great Plains, future investigations into elevated bores and their role in the structure, evolution, and maintenance of deep convection over this region are encouraged. Our findings are reminiscent of the proposal of Tepper (1950) that waves 


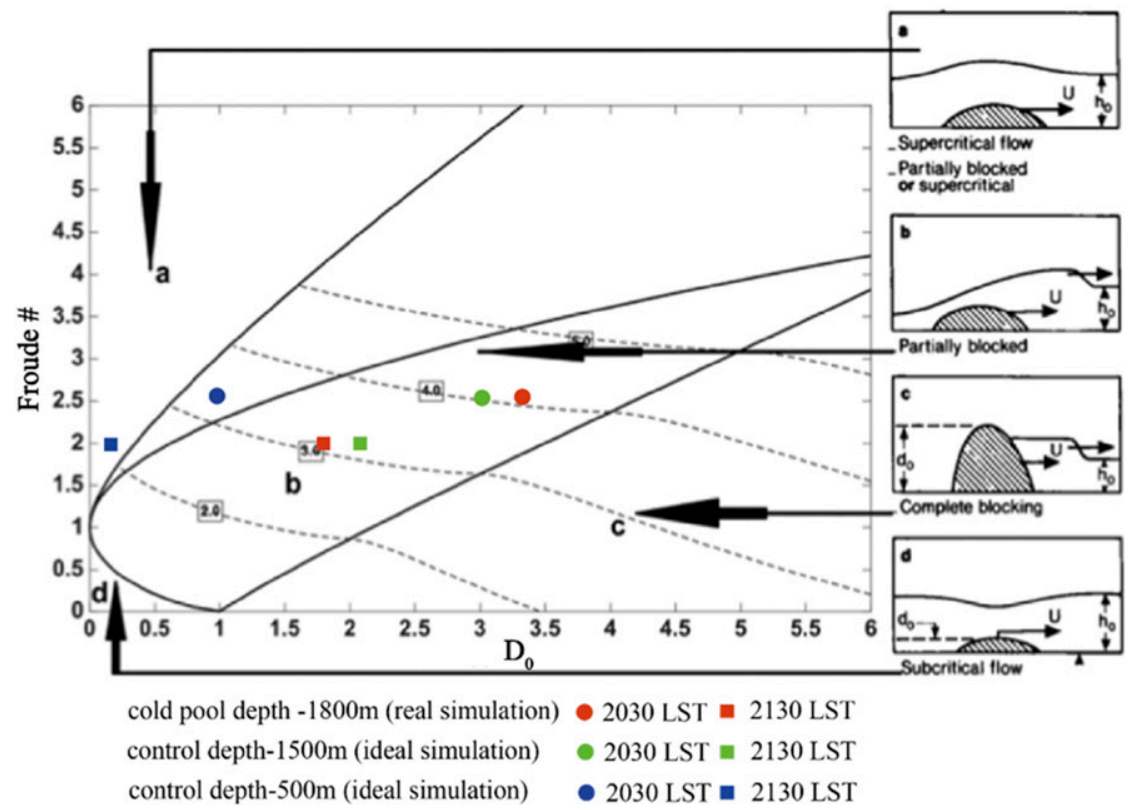

FIG. 21. Plot of the nondimensional parameter $D_{0}$ and the Froude number $F_{r}$ at 2030 and 2130 LST of different depths for the wave. The two parameter spaces indicate the predicted flow regime. Most of the points fall within regime $b$, which is a partially blocked flow where bores would be generated. The shallow cold pool in the idealized simulation using the ambient environment at 2030 LST lies in the region between zones b and a, which means either a partially blocked flow or a supercritical flow. The shallow cold pool for the flow at 2130 LST lies in the supercritical regime.

on the capping inversion could aid in the continuation of squall lines over the central United States. Noting that an inversion alone cannot act as a waveguide (Lindzen and Tung 1976), we found that wave energy would have been trapped or partially trapped by a favorable Scorer parameter. Since this feature developed in a synoptically disturbed environment with significant vertical shear, the question arises if elevated bores and destruction of the capping layer aloft is more likely in disturbed environments with enhanced vertical shear.

In addition, larger-scale averaged vertical motions and the thermodynamic impacts in the simulations suggest the presence of an $n=2$ mode long-period gravity waves (i.e., Pandya and Durran 1996; AdamsSelin and Johnson 2013). The simulated $n=2$ mode in this case is expected in response to the general distribution of buoyancy within the MCS. The possibility also exists that the elevated bore subsequently evolved toward the structure of an $n=2$ mode. Another possibility, raised by the correspondence between these two disturbances (Fovell et al. 2006; Parsons et al. 2019 ) is that the buoyancy distribution associated with the bores can generate or influence $n=2$ mode disturbances.

TABLE 2. Flow regimes, estimated variables, and values of $D_{0}$ and $F_{r}$ at 1930 and 2030 LST for different depths. The flow regime designation PB refers to partially blocked, while SP designates flow that is either supercritical or partially blocked.

\begin{tabular}{|c|c|c|c|c|c|c|}
\hline \multirow[b]{2}{*}{$h_{0}(\mathrm{~m})$} & \multicolumn{3}{|c|}{1930 LST } & \multicolumn{3}{|c|}{$2030 \mathrm{LST}$} \\
\hline & 500 & 500 & 500 & 700 & 700 & 700 \\
\hline$h(\mathrm{~m})$ & 1800 (cold pool) & 1500 (mountain) & 500 & 1300 (cold pool) & 1500 (mountain) & 500 \\
\hline$U_{a}\left(\mathrm{~m} \mathrm{~s}^{-1}\right)$ & -10 & -10 & -10 & -10 & -10 & -10 \\
\hline$U_{\mathrm{cp}}\left(\mathrm{m} \mathrm{s}^{-1}\right)$ & 7.5 & 7.5 & 10 & 10 & 10 & 10 \\
\hline$\Delta \theta_{\mathrm{vw}}(\mathrm{K})$ & 3 & 3 & 3 & 4.5 & 4.5 & 4.5 \\
\hline$\theta_{\mathrm{vw}}(\mathrm{K})$ & 311.5 & 311.5 & 311.5 & 311 & 311 & 31 \\
\hline$D_{0}$ & 3.4 & 3 & 1 & 1.86 & 2.14 & 0.71 \\
\hline$F_{r}$ & 2.55 & 2.55 & 2.55 & 2.0 & 2.0 & 2.0 \\
\hline Flow regime & $\mathrm{PB}$ & PB & $\mathrm{SP}$ & PB & PB & SP \\
\hline
\end{tabular}


Acknowledgments. We are grateful that this work was supported by the National Fundamental Research 973 Program of China (2015CB452801 and 2013CB430100), the National Natural Science Fund of China (41505046 and 41705032), and the U.S. NSF (AGS-1237404, AGS1229181, AGS-PDM 1921587). The simulations were conducted using the Boomer supercomputer at the University of Oklahoma. We greatly appreciate the comments of colleagues, Kevin R. Haghi and Dale Durran (both currently of the University of Washington) and all those scientists, engineers, technicians, pilots, flight crews and students that made the PECAN project possible. We thank the editor, Dr. Fovell, and anonymous reviewers for useful comments that greatly improved the manuscript. Interagency support from NSF, NOAA, NASA, and DOE made the PECAN field campaign possible.

\section{REFERENCES}

Adams-Selin, R. D., and R. H. Johnson, 2010: Mesoscale surface pressure and temperature features associated with bow echoes. Mon. Wea. Rev., 138, 212-227, https://doi.org/10.1175/ 2009MWR2892.1.

- , and - 2013: Examination of gravity waves associated with the 13 March 2003 bow echo. Mon. Wea. Rev., 141, 3735-3756, https://doi.org/10.1175/MWR-D-12-00343.1.

Arritt, R. W., T. D. Rink, M. Segal, D. P. Todey, C. A. Clark, M. J. Mitchell, and K. M. Labas, 1997: The Great Plains low-level jet during the warm season of 1993. Mon. Wea. Rev., 125, 2176-2192, https://doi.org/10.1175/1520-0493(1997) 125<2176:TGPLLJ > 2.0.CO;2.

Baines, P. G., 1984: A unified description of two-layer flow over topography. J. Fluid Mech., 146, 127-167, https://doi.org/ 10.1017/S0022112084001798.

Birch, C. E., D. J. Parker, A. O'Leary, J. H. Marsham, C. M. Taylor, P. P. Harris, and G. M. S. Lister, 2013: Impact of soil moisture and convectively generated waves on the initiation of a West African mesoscale convective system. Quart. J. Roy. Meteor. Soc., 139, 1712-1730, https://doi.org/10.1002/qj.2062.

Blake, B. T., D. B. Parsons, K. R. Haghi, and S. G. Castleberry, 2017: The structure, evolution, and dynamics of a nocturnal convective system simulated using the WRF-ARW Model. Mon. Wea. Rev., 145, 3179-3201, https://doi.org/10.1175/ MWR-D-16-0360.1.

Bretherton, C. S., and P. K. Smolarkiewicz, 1989: Gravity waves, compensating subsidence and detrainment around cumulus clouds. J. Atmos. Sci., 46, 740-759, https://doi.org/10.1175/ 1520-0469(1989)046<0740:GWCSAD > 2.0.CO;2.

Bryan, G. H., and M. D. Parker, 2010: Observations of a squall line and its near environment using high-frequency rawinsonde launches during VORTEX2. Mon. Wea. Rev., 138, 4076-4097, https://doi.org/10.1175/2010MWR3359.1.

Carbone, R. E., and J. D. Tuttle, 2008: Rainfall occurrence in the U.S. warm season: The diurnal cycle. J. Atmos. Sci., 21, 4132 4146, https://doi.org/10.1175/2008JCLI2275.1.

- J. W. Conway, N. A. Crook, and M. W. Moncrieff, 1990: The generation and propagation of a nocturnal squall line. Part I: Observations and implications for mesoscale predictability.
Mon. Wea. Rev., 118, 26-49, https://doi.org/10.1175/15200493(1990) $118<0026$ :TGAPOA $>2.0$. CO;2.

Chasteen, M. B., S. E. Koch, and D. B. Parsons, 2019: Multiscale processes enabling the longevity and daytime persistence of a nocturnal mesoscale convective system. Mon. Wea. Rev., 147, 733-761, https://doi.org/10.1175/MWR-D-18-0233.1.

Chipilski, H. G., X. Wang, and D. B. Parsons, 2018: Object-based algorithm for the identification and tracking of convective outflow boundaries in numerical models. Mon. Wea. Rev., 146, 4179-4200, https://doi.org/10.1175/MWR-D-18-0116.1.

Chou, M.-D., and M. J. Suarez, 1999: A solar radiation parameterization for atmospheric studies. NASA Tech. Rep. TM1999-104606, Vol. 15, 38 pp., https://gmao.gsfc.nasa.gov/pubs/ docs/Chou136.pdf.

Coleman, T. A., and K. R. Knupp, 2011: Radiometer and profiler analysis of the effects of a bore and a solitary wave on the stability of the nocturnal boundary layer. Mon. Wea. Rev., 139, 211-223, https://doi.org/10.1175/2010MWR3376.1.

Corfidi, S. F., S. J. Corfidi, and D. M. Schultz, 2008: Elevated convection and castellanus: Ambiguities, significance, and questions. Wea. Forecasting, 23, 1280-1303, https://doi.org/ 10.1175/2008WAF2222118.1.

Cotton, W. R., R. L. George, P. J. Wetzel, and R. L. McAnelly, 1983: A long-lived mesoscale convective complex. Part I: The mountaingenerated component. Mon. Wea. Rev., 111, 1893-1918, https:// doi.org/10.1175/1520-0493(1983)111<1893:ALLMCC>2.0.CO;2.

Crook, N. A., 1988: Trapping of low-level internal gravity waves. J. Atmos. Sci., 45, 1533-1541, https://doi.org/10.1175/15200469(1988)045<1533:TOLLIG > 2.0.CO;2.

Curtis, R. C., and H. A. Panofsky, 1958: The relation between largescale vertical motion and weather in summer. Bull. Amer. Meteor. Soc., 39, 521-531, https://doi.org/10.1175/1520-0477-39.10.521.

Ek, M. B., K. E. Mitchell, Y. Lin, E. Rogers, P. Grummann, V. Koren, G. Gayno, and J. D. Tarpley, 2003: Implementation of Noah land surface model advances in the National Centers for Environmental Prediction operational mesoscale eta Model. J. Geophys. Res., 108, 8851, https://doi.org/10.1029/2002JD003296.

Fovell, R. G., 2002: Upstream influence of numerically simulated squall-line storms. Quart. J. Roy. Meteor. Soc., 128, 893-912, https://doi.org/10.1256/0035900021643737.

, G. L. Mullendore, and S. H. Kim, 2006: Discrete propagation in numerically simulated nocturnal squall lines. Mon. Wea. Rev., 134, 3735-3752, https://doi.org/10.1175/MWR3268.1.

French, A. J., and M. D. Parker, 2010: The response of simulated nocturnal convective systems to a developing low-level jet. J. Atmos. Sci., 67, 3384-3408, https://doi.org/10.1175/2010JAS3329.1.

Geerts, B., and Coauthors, 2017: The 2015 Plains Elevated Convection at Night field project. Bull. Amer. Meteor. Soc., 98, 767-786, https://doi.org/10.1175/BAMS-D-15-00257.1.

Haghi, K. R., D. B. Parsons, and A. Shapiro, 2017: Bores observed during IHOP_2002: The relationship of bores to the nocturnal environment. Mon. Wea. Rev., 145, 3929-3946, https://doi.org/ 10.1175/MWR-D-16-0415.1.

_ and Coauthors, 2019: Bore-ing into nocturnal convection. Bull. Amer. Meteor. Soc., 100, 1103-1121, https://doi.org/ 10.1175/BAMS-D-17-0250.1.

Hartung, D. C., J. A. Otkin, J. E. Martin, and D. D. Turner, 2010: The life cycle of an undular bore and its interaction with a shallow, intense cold front. Mon. Wea. Rev., 138, 886-908, https://doi.org/10.1175/2009MWR3028.1.

Houghton, D. D., and A. Kasahara, 1968: Nonlinear shallow fluid flow over an isolated ridge. Commun. Pure Appl. Math., 21, 1-23, https://doi.org/10.1002/cpa.3160210103. 
Houze, R. A., Jr., S. A. Rutledge, M. I. Biggerstaff, and B. F. Smull, 1989: Interpretation of Doppler weather radar displays of midlatitude mesoscale convective systems. Bull. Amer. Meteor. Soc., 70, 608-619, https://doi.org/10.1175/15200477(1989)070<0608:IODWRD>2.0.CO;2.

Jahn, D. E., and W. A. Gallus Jr., 2018: Impacts of modifications to a local planetary boundary layer scheme on forecasts of the Great Plains low-level jet environment. Wea. Forecasting, 33, 1109-1120, https://doi.org/10.1175/WAF-D-18-0036.1.

Janjić, Z. I., 1994: The step-mountain eta coordinate model: Further developments of the convection, viscous sublayer, and turbulence closure schemes. Mon. Wea. Rev., 122, 927-945, https://doi.org/ 10.1175/1520-0493(1994)122<0927:TSMECM >2.0.CO;2.

Johnson, A., and X. Wang, 2017: Design and implementation of a GSI-based convection-allowing ensemble data assimilation and forecast system for the PECAN field experiment. Part I: Optimal configurations for nocturnal convection prediction using retrospective cases. Wea. Forecasting, 32, 289-315, https://doi.org/10.1175/WAF-D-16-0102.1.

Keenan, T. D., and R. E. Carbone, 2008: Propagation and diurnal evolution of warm season cloudiness in the Australian and Maritime Continent region. Mon. Wea. Rev., 136, 973-994, https://doi.org/10.1175/2007MWR2152.1.

Knupp, K., 2006: Observational analysis of a gust front to bore to solitary wave transition within an evolving nocturnal boundary layer. J. Atmos. Sci., 63, 2016-2035, https://doi.org/10.1175/ JAS3731.1.

Koch, S. E., and W. L. Clark, 1999: A nonclassical cold front observed during COPS-91: Frontal structure and the process of severe storm initiation. J. Atmos. Sci., 56, 2862-2890, https://doi.org/ 10.1175/1520-0469(1999)056<2862:ANCFOD>2.0.CO;2.

_ , P. Dorian, B. Ferrare, R. Melfi, S. H. Skillman, C. William, and D. Whiteman, 1991: Structure of an internal bore and dissipating gravity current as revealed by Raman lidar. Mon. Wea. Rev., 119, 857-887, https://doi.org/10.1175/15200493(1991)119<0857:SOAIBA > 2.0.CO;2.

, W. Feltz, F. Fabry, M. Pagowski, B. Geerts, K. M. Bedka, D. O. Miller, and J. W. Wilson, 2008a: Turbulent mixing processes in atmospheric bores and solitary waves deduced from profiling systems and numerical simulation. Mon. Wea. Rev., 136, 1373-1400, https://doi.org/10.1175/2007MWR2252.1.

_ C. Flamant, J. W. Wilson, B. M. Gentry, and B. D. Jamison, 2008b: An atmospheric soliton observed with Doppler radar, differential absorption lidar, and a molecular Doppler lidar. J. Atmos. Oceanic Technol., 25, 1267-1287, https://doi.org/ 10.1175/2007JTECHA951.1.

Lane, T. P., and M. J. Reeder, 2001: Convectively generated gravity waves and their effect on the cloud environment. J. Atmos. Sci., 58, 2427-2440, https://doi.org/10.1175/1520-0469(2001) 058<2427:CGGWAT>2.0.CO;2.

—, and F. Zhang, 2011: Coupling between gravity waves and tropical convection at mesoscales. J. Atmos. Sci., 68 , 2582-2598, https://doi.org/10.1175/2011JAS3577.1.

Lindzen, R. S., and K. K. Tung, 1976: Banded convective activity and ducted gravity waves. Mon. Wea. Rev., 104, 1602-1617, https://doi.org/10.1175/1520-0493(1976)104<1602: BCAADG $>2.0 . \mathrm{CO} ; 2$.

Long, R. R., 1955: Some aspects of the flow of stratified fluids. Tellus, 7, 341-357, https://doi.org/10.3402/tellusa.v7i3.8900.

Loveless, D. M., T. J. Wagner, D. D. Turner, S. A. Ackerman, and W. F. Feltz, 2019: A composite perspective on bore passages during the PECAN campaign. Mon. Wea. Rev., 147, 1395-1413, https://doi.org/10.1175/MWR-D-18-0291.1.
Maddox, R. A., 1983: Large-scale meteorological conditions associated with midlatitude, mesoscale convective complexes. Mon. Wea. Rev., 111, 1475-1493, https://doi.org/10.1175/15200493(1983)111<1475:LSMCAW>2.0.CO;2.

_ C. F. Chappell, and L. R. Hoxit, 1979: Synoptic and meso- $\alpha$ scale aspects of flash flood events. Bull. Amer. Meteor. Soc., 60, 115-123, https://doi.org/10.1175/1520-0477-60.2.115.

_ , F. Canova, and L. R. Hoxit, 1980: Meteorological characteristics of flash flood events over the western United States. Mon. Wea. Rev., 108, 1866-1877, https://doi.org/10.1175/15200493(1980)108<1866:MCOFFE > 2.0.CO;2.

Mapes, B. E., 1993: Gregarious tropical convection. J. Atmos. Sci., 50, 2026-2037, https://doi.org/10.1175/1520-0469(1993)050<2026: GTC $>2.0 . \mathrm{CO} ; 2$.

Marsham, J. H., S. B. Trier, T. M. Weckwerth, and J. W. Wilson, 2011: Observations of elevated convection initiation leading to a surface-based squall line during 13 June IHOP_2002. Mon. Wea. Rev., 139, 247-271, https://doi.org/ 10.1175/2010MWR3422.1.

Martin, E. R., and R. H. Johnson, 2008: An observational and modeling study of an atmospheric internal bore during NAME 2004. Mon. Wea. Rev., 136, 4150-4167, https://doi.org/10.1175/ 2008MWR2486.1.

Means, L. L., 1952: On thunderstorm forecasting in the central United States. Mon. Wea. Rev., 80, 165-189, https://doi.org/ 10.1175/1520-0493(1952)080<0165:OTFITC $>2.0 . C O ; 2$.

Mesinger, F., and Coauthors, 2006: North American Regional Reanalysis. Bull. Amer. Meteor. Soc., 87, 343-360, https:// doi.org/10.1175/BAMS-87-3-343.

Mlawer, E. J., S. J. Taubman, P. D. Brown, M. J. Iacono, and S. A. Clough, 1997: Radiative transfer for inhomogeneous atmospheres: RRTM, a validated correlated-k model for the longwave. J. Geophys. Res., 102, 16 663-16 682, https:// doi.org/10.1029/97JD00237.

Morrison, H., and J. A. Milbrandt, 2015: Parameterization of cloud microphysics based on the prediction of bulk ice particle properties. Part I: Scheme description and idealized tests. J. Atmos. Sci., 72, 287-311, https://doi.org/10.1175/JAS-D-14-0065.1.

_, G. Thompson, and V. Tatarskii, 2009: Impact of cloud microphysics on the development of trailing stratiform precipitation in a simulated squall line: Comparison of one- and two-moment schemes. Mon. Wea. Rev., 137, 991-1007, https://doi.org/10.1175/ 2008MWR2556.1.

Nakanishi, M., and H. Niino, 2004: An improved Mellor-Yamada level-3 model with condensation physics: Its design and verification. Bound.-Layer Meteor., 112, 1-31, https://doi.org/ 10.1023/ B:BOUN.0000020164.04146.98.

Nicholls, M. E., R. A. Pielke, and W. R. Cotton, 1991: Thermally forced gravity waves in an atmosphere at rest. J. Atmos. Sci., 48, 1869-1884, https://doi.org/10.1175/1520-0469(1991)048<1869: TFGWIA $>2.0 . \mathrm{CO} ; 2$.

Pandya, R. E., and D. R. Durran, 1996: The influence of convectively generated thermal forcing on the mesoscale circulation around squall lines. J. Atmos. Sci., 53, 2924-2951, https://doi.org/10.1175/ 1520-0469(1996)053<2924:TIOCGT>2.0.CO;2.

Parker, M. D., 2008: Response of simulated squall lines to low-level cooling. J. Atmos. Sci., 65, 1323-1341, https://doi.org/10.1175/ 2007JAS2507.1.

— central United States. Mon. Wea. Rev., 135, 3707-3727, https:// doi.org/10.1175/2007MWR2098.1.

Parsons, D. B., K. R. Haghi, K. T. Halbert, B. Elmer, and J. Wang, 2019: The potential role of atmospheric bores and gravity 
waves in the initiation and maintenance of nocturnal convection over the Southern Great Plains. J. Atmos. Sci., 76, 43-68, https://doi.org/10.1175/JAS-D-17-0172.1.

Pitchford, K. L., and J. London, 1962: The low-level jet as related to nocturnal thunderstorms over midwest United States. J. Appl. Meteor., 1, 43-47, https://doi.org/10.1175/1520-0450(1962) 001<0043:TLLJAR>2.0.CO;2.

Rottman, J. W., and J. E. Simpson, 1989: The formation of internal bores in the atmosphere: A laboratory model. Quart. J. Roy. Meteor. Soc., 115, 941-963, https://doi.org/10.1002/qj.49711548809.

Rotunno, R., J. B. Klemp, and M. L. Weisman, 1988: A theory for strong, long-lived squall lines. J. Atmos. Sci., 45, 463-485, https:// doi.org/10.1175/1520-0469(1988)045<0463:ATFSLL > 2.0.CO;2.

Schmidt, J. M., and W. R. Cotton, 1990: Interactions between upper and lower tropospheric gravity waves on squall line structure and maintenance. J. Atmos. Sci., 47, 12051222, https://doi.org/10.1175/1520-0469(1990)047<1205: IBUALT $>2.0 . \mathrm{CO} ; 2$.

Scorer, R. S., 1949: Theory of waves in the lee of mountains. Quart. J. Roy. Meteor. Soc., 75, 41-56, https://doi.org/10.1002/ qj.49707532308.

Shapiro, A., E. Fedorovich, and S. Rahimi, 2016: A unified theory for the Great Plains nocturnal low-level jet. J. Atmos. Sci., 73, 3037-3057, https://doi.org/10.1175/JAS-D-15-0307.1.

,-- , and J. G. Gebauer, 2018: Mesoscale ascent in nocturnal low-level jets. J. Atmos. Sci., 75, 1403-1427, https://doi.org/ 10.1175/JAS-D-17-0279.1.

Skamarock, W. C., and Coauthors, 2008: A description of the Advanced Research WRF version 3. NCAR Tech. Note NCAR/ TN-475+STR, 113 pp., https://doi.org/10.5065/D68S4MVH.

Stephan, C. C., M. J. Alexander, M. Hedlin, C. D. de Groot-Hedlin, and L. Hoffmann, 2016: A case study on the far-field properties of propagating tropospheric gravity waves. Mon. Wea. Rev., 144, 2947-2961, https://doi.org/10.1175/MWR-D-16-0054.1.

Tanamachi, R. L., W. F. Feltz, and M. Xue, 2008: Observations and numerical simulation of upper boundary layer rapid drying and moistening events during the International $\mathrm{H}_{2} \mathrm{O}$ Project (IHOP_2002). Mon. Wea. Rev., 136, 3106-3120, https:// doi.org/10.1175/2008MWR2204.1.

Tepper, M. A., 1950: proposed mechanism of squall lines: The pressure jump line. J. Atmos. Sci., 7, 21-29, https://doi.org/ 10.1175/1520-0469(1950)007<0021:APMOSL>2.0.CO;2.

Trier, S. B., and D. B. Parsons, 1993: Evolution of environmental conditions preceding the development of a nocturnal mesoscale convective complex. Mon. Wea. Rev., 121, 1078-1098, https://doi.org/10.1175/1520-0493(1993)121<1078:EOECPT> 2.0.CO;2.

,-- , and J. H. Clark, 1991: Environment and evolution of a cold-frontal mesoscale convective system. Mon. Wea. Rev., 119, 2429-2455, https://doi.org/10.1175/1520-0493(1991) $119<2429$ :EAEOAC $>2.0 . \mathrm{CO} ; 2$.

Tuttle, J. D., and C. A. Davis, 2006: Corridors of warm season precipitation in the central United States. Mon. Wea. Rev., 134, 2297-2317, https://doi.org/10.1175/MWR3188.1.

Uccelini, L. W., 1975: A case study of apparent gravity wave initiation of severe convective storms. Mon. Wea. Rev., 103, 497-513, https://doi.org/10.1175/1520-0493(1975)103<0497: ACSOAG $>2.0 . \mathrm{CO} ; 2$.

—_ and D. R. Johnson, 1979: The coupling of upper and lower tropospheric jet streaks and implications for the development of severe convective storms. Mon. Wea. Rev., 107, 682-703, https://doi.org/10.1175/1520-0493(1979)107<0682: TCOUAL $>2.0 . \mathrm{CO} ; 2$

Wakimoto, R. M., and D. E. Kingsmill, 1995: Structure of an atmospheric undular bore generated from colliding boundaries during CaPE. Mon. Wea. Rev., 123, 1374-1393, https://doi.org/ 10.1175/1520-0493(1995)123<1374:SOAAUB > 2.0.CO;2.

Wallace, J. M., 1975: Diurnal variations in precipitation and thunderstorm frequency over the conterminous United States. Mon. Wea. Rev., 103, 406-419, https://doi.org/10.1175/15200493(1975)103<0406:DVIPAT > 2.0.CO;2.

Weckwerth, T. M., and Coauthors, 2004: An overview of the International $\mathrm{H}_{2} \mathrm{O}$ Project (IHOP_2002) and some preliminary highlights. Bull. Amer. Meteor. Soc., 85, 253-277, https:// doi.org/10.1175/BAMS-85-2-253.

Wilson, J. W., and R. D. Roberts, 2006: Summary of convective storm initiation and evolution during IHOP: Observational and modeling perspective. Mon. Wea. Rev., 134, 23-47, https:// doi.org/10.1175/MWR3069.1.

Zhang, D. L., and W. Z. Zheng, 2004: Diurnal cycles of surface winds and temperatures as simulated by five boundary layer parameterizations. J. Appl. Meteor., 43, 157-169, https://doi.org/10.1175/1520-0450(2004)043<0157:DCOSWA > 2.0.CO;2.

Zhang, H., Z. Pu, and X. Zhang, 2013: Examination of errors in near-surface temperature and wind from WRF numerical simulations in regions of complex terrain. Wea. Forecasting, 28, 893-914, https://doi.org/10.1175/WAF-D-12-00109.1. 